San Jose State University

SJSU ScholarWorks

Mineta Transportation Institute Publications

$2-2020$

\title{
The Potential for Autonomous Vehicle Technologies to Address Barriers to Driving for Individuals with Autism
}

Caroline Rodier

University of California, Davis

Follow this and additional works at: https://scholarworks.sjsu.edu/mti_publications

Part of the Civil Engineering Commons, and the Transportation Engineering Commons

\section{Recommended Citation}

Caroline Rodier. "The Potential for Autonomous Vehicle Technologies to Address Barriers to Driving for Individuals with Autism" Mineta Transportation Institute Publications (2020). https://doi.org/10.31979/ mti.2020.1706

This Report is brought to you for free and open access by SJSU ScholarWorks. It has been accepted for inclusion in Mineta Transportation Institute Publications by an authorized administrator of SJSU ScholarWorks. For more information, please contact scholarworks@sjsu.edu. 
SJSU UNIVSESITY

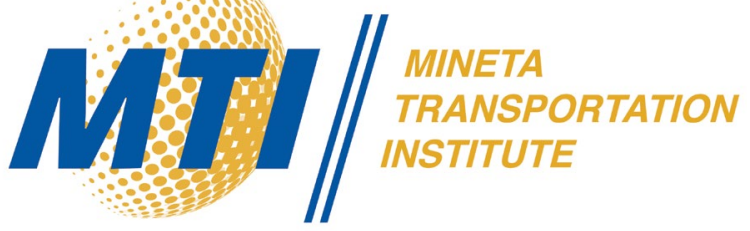

The Potential for Autonomous Vehicle Technologies to Address Barriers to Driving for Individuals with Autism

Caroline Rodier, PhD

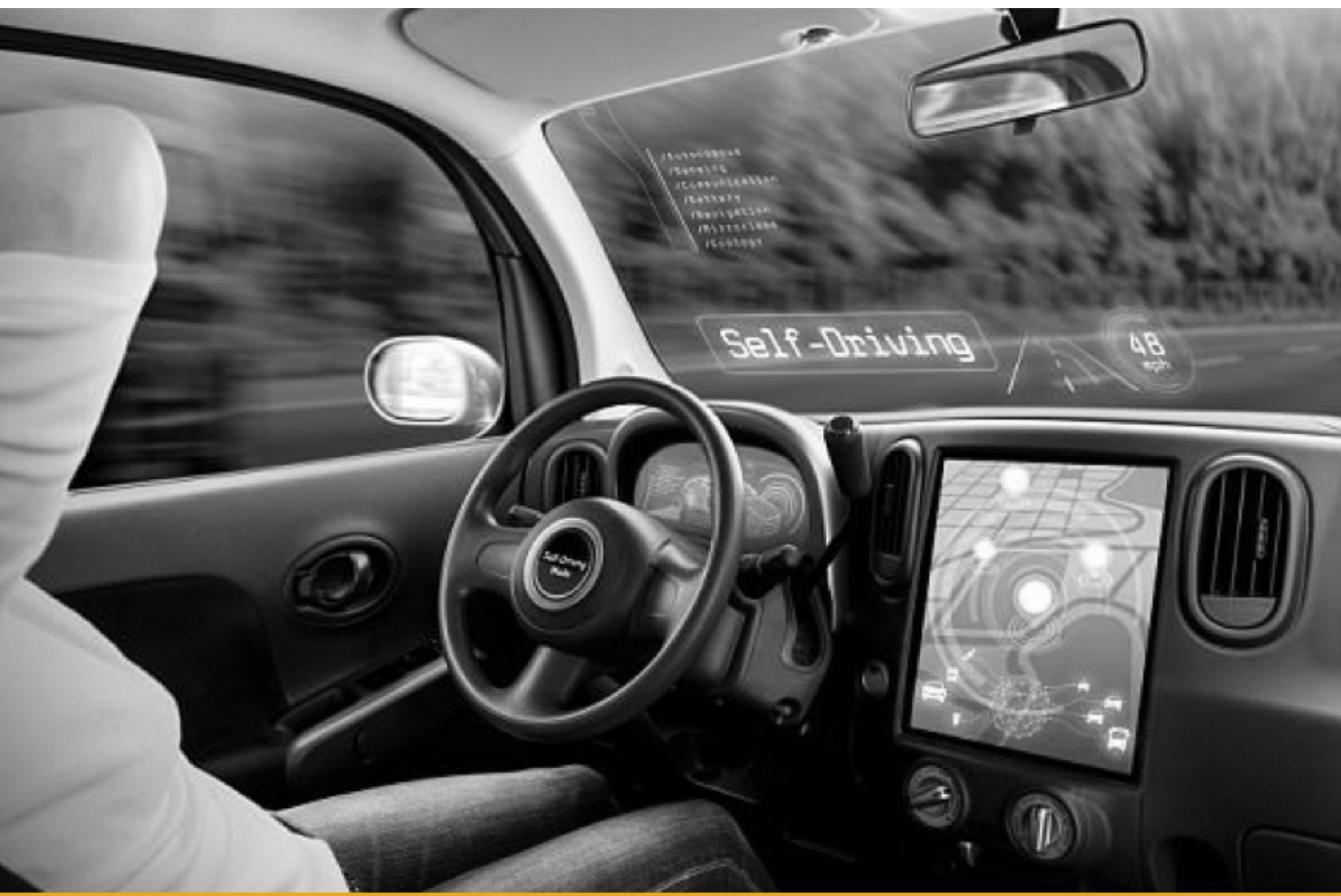




\section{MINETA TRANSPORTATION INSTITUTE \\ LEAD UNIVERSITY OF \\ Mineta Consortium for Transportation Mobility}

Founded in 1991, the Mineta Transportation Institute (MTI), an organized research and training unit in partnership with the Lucas College and Graduate School of Business at San José State University (SJSU), increases mobility for all by improving the safety, efficiency, accessibility, and convenience of our nation's transportation system. Through research, education, workforce development, and technology transfer, we help create a connected world. MTI leads the four-university Mineta Consortium for Transportation Mobility, a Tier I University Transportation Center funded by the U.S. Department of Transportation's Office of the Assistant Secretary for Research and Technology (OST-R), the California Department of Transportation (Caltrans), and by private grants and donations.

MTl's transportation policy work is centered on three primary responsibilities:

\section{Research}

MTI works to provide policy-oriented research for all levels of government and the $P$ rivate sector to foster the development of optimum surface transportation systems. Research areas include: bicycle and pedestrian issues; financing public and private sector transportation improvements; intermodal connectivity and integration; safety and security of transportation systems; sustainability of transportation systems; transportation / land use / environment; and transportation planning and policy development. Certified Research Associates conduct the research. Certification requires an advanced degree, generally a Ph.D., a record of academic publications, and professional references. Research projects culminate in a peer-reviewed publication, available on TransWeb, the MTI website (http://transweb.sjsu.edu).

\section{Education}

The Institute supports education programs for students seeking a career in the development and operation of surface transportation systems. MTI, through San José State University, offers an AACSBaccredited Master of Science in Transportation Management and graduate certificates in Transportation Management,Transportation Security, and High-Speed Rail Management that serve to prepare the nation's transportation managers for the 2 I st century. With the active assistance of the California Department of Transportation (Caltrans), MTI delivers its classes over a state-of-the-art videoconference network throughout the state of California and via webcasting beyond, allowing working transportation professionals to pursue an advanced degree regardless of their location. To meet the needs of employers seeking a diverse workforce, MTl's education program promotes enrollment to under-represented groups.

\section{Information and Technology Transfer}

MTI utilizes a diverse array of dissemination methods and media to ensure research results reach those responsible for managing change. These methods include publication, seminars, workshops, websites, social media, webinars, and other technology transfer mechanisms. Additionally, MTI promotes the availability of completed research to professional organizations and journals and works to integrate the research findings into the graduate education program.MTI's extensive collection of transportation- related publications is integrated into San José State University's world-class Martin Luther King, Jr. Library.

\section{Disclaimer}

The contents of this report reflect the views of the authors, who are responsible for the facts and accuracy of the information presented herein. This document is disseminated in the interest of information exchange. The report is funded, partially or entirely, by a grant from the U.S. Department of Transportation's University Transportation Centers Program. This report does not necessarily reflect the official views or policies of the U.S. government, State of California, or the Mineta Transportation Institute, who assume no liability for the contents or use thereof. This report does not constitute a standard specification, design standard, or regulation. 
REPORT 20-01

\section{THE POTENTIAL FOR AUTONOMOUS VEHICLE TECHNOLOGIES TO ADDRESS BARRIERS TO DRIVING FOR INDIVIDUALS WITH AUTISM}

Caroline Rodier, $\mathrm{PhD}$

February 2020

A publication of

Mineta Transportation Institute

Created by Congress in 1991

College of Business

San José State University

San José, CA 95192-0219 


\section{TECHNICAL REPORT DOCUMENTATION PAGE}

1. Report No. 20-01

4. Title and Subtitle

The Potential for Autonomous Vehicle Technologies to Address Barriers to Driving fo Individuals with Autism

7. Authors

Caroline Rodier, PhD https://orcid.org/ 0000-0002-9107-5547

2. Government Accession No.

3. Recipient's Catalog No.

5. Report Date

February 2020

6. Performing Organization Code

8. Performing Organization Report CA-MTI-1706

10. Work Unit No.

11. Contract or Grant No. 69A3551747127

San José State University

San José, CA 95192-0219

12. Sponsoring Agency Name and Address

U.S. Department of Transportation

Office of the Assistant Secretary for

Research and Technology

University Transportation Centers Program

1200 New Jersey Avenue, SE

Washington, DC 20590

15. Supplemental Notes

DOI: $10.31979 / \mathrm{mti} .2020 .1706$

\section{Abstract}

Individuals with autism represent a sizeable share of the U.S. population (almost $2 \%$ ), and nearly half of those with autism have average to high levels of intelligence. However, available research shows that adults with autism have a much more difficult time becoming employed and living independently compared to both typically developing adults and adults with disabilities. This study reviews the available literature on the magnitude of challenges to driving and accessing essential opportunities for adults with autism, and the potential of autonomous vehicles to address those challenges. This study is unique in that it identifies the specific driving challenges and needs faced by those with autism. The study makes the following recommendations: (1) Occupational therapists certified for driving rehabilitation should evaluate the driving abilities of those with autism and provide enhanced driver training, with and without autonomous vehicle technologies (i.e., warning systems, steering, acceleration/deceleration, and braking systems) to address any driving challenges; (2) If autonomous vehicle technology is shown in (1) to be necessary to allow for safe driving, then public funding should be made available to help with its purchase, just as funding is currently made available for those with physical disabilities to modify vehicles with adaptive equipment; (3) More tests of high automation should be conducted to affordably expand transit access; however, in the interim, public funding should be made available to subsidize ride-hailing services when transit is not a feasible travel option for those with autism; and (4) More research is needed to evaluate the effectiveness of autonomous vehicle technology interventions for driving (in 1) and expanding transit access (in 3 ).

\section{Key Words}

Autism, access, driving, autonomous vehicles

\section{Distribution Statement}

No restrictions. This document is available to the public through The National Technical Information Service, Springfield, VA 22161
19. Security Classif. (of this report) Unclassified
20. Security Classif. (of this page) Unclassified
21. No. of Pages

41
22. Price 


\title{
Copyright $\odot 2020$ \\ by Mineta Transportation Institute \\ All rights reserved
}

DOI: 10.31979/mti.2020.1706

\author{
Mineta Transportation Institute \\ College of Business \\ San José State University \\ San José, CA 95192-0219 \\ Tel: (408) 924-7560 \\ Fax: (408) 924-7565 \\ Email: mineta-institute@sjsu.edu
}

transweb.sjsu.edu 


\section{ACKNOWLEDGMENTS}

The authors thank Editing Press, for editorial services, as well as MTI staff, including Executive Director Karen Philbrick, PhD; Deputy Executive Director Hilary Nixon, PhD; Graphic Designer Alverina Eka Weinardy; and Executive Administrative Assistant Jill Carter. 


\section{TABLE OF CONTENTS}

Executive Summary 1

I. Introduction 3

$\begin{array}{lr}\text { II. Background } & 4\end{array}$

III. Diagnostic Challenges and Their Potential Effect on Driving Performance 7

IV. Literature Review of the Evidence Linking Factors Associated with $\begin{array}{ll}\text { Autism to Driving Performance } & 10\end{array}$

$\begin{array}{ll}\text { V. Autonomous Vehicles } & 22\end{array}$

VI. Conclusions and Policy Recommendations 25

$\begin{array}{lr}\text { Endnotes } & 27\end{array}$

$\begin{array}{ll}\text { Bibliography } & 35\end{array}$

$\begin{array}{ll}\text { About the Author } & \mathbf{4 0}\end{array}$

$\begin{array}{ll}\text { Peer Review } & 41\end{array}$ 


\section{LIST OF TABLES}

1. Descriptive Statistics Comparing Independent Living Outcomes for Young Adults in the General Population, Classified as Disabled, and Classified with Autism Only

2. Autism Diagnostic Factors, General Lay Definition, and Application to Driving 9

3. Summary of Studies on Driving Performance and Causal Factors for Individuals with Autism

4. Summary of Study Results by Skill 


\section{EXECUTIVE SUMMARY}

Many of us have family, friends, or acquaintances with a developmental disability known as autism. In fact, according to the latest estimates from the U.S. Center for Disease Control (CDC), one in 59 (or 1.7\%) of children have autism, and almost half of those with autism have average to high levels of intelligence. Over the next ten years, nearly threequarters of a million young people with autism will become adults. Research shows that adults with autism have a much harder time becoming employed and living independently compared to both typically developing adults and adults with disabilities.

This study reviews the evidence on the magnitude of the problem of driving and access for those with autism, and the potential of autonomous vehicles to address these challenges. The review uses the Society of Automotive Engineers' (SAE) levels of automation 0 to 5 (that is, no vehicle automation to fully autonomous vehicles). Fully autonomous vehicles (SAE level 5) could solve key driving challenges associated with autism. However, it is unlikely that these vehicles will be publicly available in the foreseeable future due to immense technological, infrastructural, and institutional barriers to implementation.

The synthesis of the literature in this study reveals that many of the diagnostic factors associated with autism may contribute to driving difficulties. Broadly, these factors include challenges in executive function, social-cognitive, motor, sensory perception, and integration of sensory-motor skills. Drivers must possess adequate executive functioning abilities to monitor and focus on the road ahead and adapt to changes in roadway conditions to arrive safely at their destination. Social-cognitive skills include the ability to identify driving hazards that are, by nature, social: for example, predicting the actions of other drivers, pedestrians, and bicyclists, and using non-verbal gestures and signals to communicate. The ability to adequately perceive visual and auditory information is necessary for effective executive functioning. It must be integrated with motor skills (both fine and gross) to execute decisions that safely address changing roadway conditions. The limited number of exploratory research studies that examine the relationship between these challenges and driving performance provides evidence to support linkages.

Currently, available legislation and programs provide funding for adolescents and adults with autism to take individualized transit training courses, use of subsidized or free transit passes, and access to paratransit if safety is a concern. However, most people in the U.S.-not just people with autism-do not have access to transit of high enough quality to enable them to meet their basic travel needs (i.e., work, education, health, shopping, personal, business, and social). SAE level 4 automation is a promising option to expand transit access in lower-density environments affordably. This level of automation allows vehicles to travel at low speeds, on roads that are in excellent condition (i.e., few potholes), and under certain weather conditions (i.e., no snow or rain). In the interim, public funding should be made available to subsidize ride-hailing services when transit is not a feasible travel option. We need funding to implement and research to evaluate the effectiveness of experimental pilots of these programs.

The review of the literature reveals that occupational therapists certified for driving 
rehabilitation (OT-DRS) can evaluate adolescents and adults with autism for driving competency and specific impairments that might impede driving skill. Children with autism frequently receive occupational therapy to support educational achievement. Schools are required to develop plans to help adolescents with disabilities transition into adulthood. Schools, regional centers, and rehabilitative services should be required to inform adolescents and adults with autism about driving evaluations and special training programs. This therapy should also include experimentation with SAE levels 0 to 2 autonomous vehicle technologies (i.e., warning systems, steering, acceleration/deceleration, and braking systems) that are currently publicly available. If therapists determine a significant benefit, then public funding should be made available to allow people with autism to purchase vehicles with recommended technologies. Currently, public funding is available for those with physical disabilities from a variety of public sources to buy or finance adaptive equipment, such as hand controls, and modify a vehicle to use the equipment and transport wheelchairs. When determined to be effective, public funding should be available to help those with autism purchase of autonomous vehicle technology, just as funding is available tor those with physical disabilities to modify vehicles with adaptive equipment. A coordinated research evaluation program should be developed and adopted to improve and measure driving outcomes from driver training programs and the use of autonomous vehicle technology. 


\section{INTRODUCTION}

Media and policy advocacy reports often cite broad potential benefits of autonomous vehicles for those who face physical, sensory, and cognitive challenges to travel. ${ }^{1}$ Of course, fully autonomous vehicles that are made accessible to populations that face these challenges could eliminate barriers to access. It is unlikely, however, that such vehicles will be widely available to the public in the foreseeable future due to the immense technological, infrastructure, and institutional barriers to implementation. In the meantime, we need research that identifies the specific driving challenges faced by different populations and the near-and longer-term capabilities of autonomous vehicle technologies to address those challenges. ${ }^{2}$ Such research is necessary to make targeted recommendations for vehicle design, ${ }^{3}$ policy and legislation, ${ }^{4}$ and intervention services to increase access. ${ }^{5}$

This study focuses on the driving needs of adults with autism, a condition clinically labeled as Autism Spectrum Disorder (or ASD). The study approach is to summarize the literature on the significance of the driving challenges for those with autism, how diagnostic factors associated with autism may contribute to difficulties driving, and the quality of the evidence supporting linkages between these challenges and driving performance. The study then identifies specific features of autonomous vehicle technology that may address critical challenges. These features are classified by the Society of Automotive Engineers' (SAE) levels of automation 0 to 5 (no vehicle automation to fully autonomous vehicles). Finally, the study makes recommendations for research, policies, interventions, and services for individuals with autism. 


\section{BACKGROUND}

Many of us have family, friends, or acquaintances with autism. In fact, according to the latest estimates from the U.S. Center for Disease Control (CDC), one in 59 (or 1.7\%) of children aged eight identified as having autism and almost half of those with autism have average to high levels of intelligence (sometimes referred to as higher functioning). ${ }^{6}$ The 2018 National Autism Indicator Report estimates 72,800 individuals with autism turned 18 in 2018. ${ }^{7}$ Over the next ten years, almost three-quarters of a million young people with autism will become adults. ${ }^{8}$

The CDC also notes that because of the diverse mix of challenges-social, emotional, and intellectual-faced by those with autism, some need more help than others in carrying out the activities of daily living as they transition from life as a child to adulthood. ${ }^{9}$ Research conducted with the data from the National Longitudinal Transition Study (NLS2) shows that adults with autism have a much harder time achieving the milestones of independent living compared to both typically developing adults and all adults with challenges. ${ }^{10}$ The NLS2 is a nationally representative survey of secondary students who received special education services. ${ }^{11}$ Researchers administered five waves of the survey from 2001 to 2009, and sample sizes are sufficiently larger to generalize to the larger population of individuals with autism. ${ }^{12}$ Previous research on autism and the achievement of measures of independence suffered from small sample sizes. ${ }^{13}$

Table 1 below shows summary statistics that compare descriptive statistics of outcomes for the general population, all those classified with special education needs, and those classified as only with autism from a 2011 study documenting the methods and results of the NLS2 survey. ${ }^{14}$ Note that all figures are from the 2011 NLS2 study, except for the employment measure (i.e., at least one paying job eight years after graduating). ${ }^{15}$ All figures are for comparable young adult age ranges. The results of the descriptive statistics in Table 1 shows that outcomes for individuals with autism are lower for post-secondary education, employment, wages, and ability to live independently than both the general population and all individuals classified as having special education needs. The magnitude of differences in achievement are sizeable. 
Table 1. Descriptive Statistics Comparing Independent Living Outcomes for Young Adults in the General Population, Classified as Disabled, and Classified with Autism Only

\begin{tabular}{lccc}
\multicolumn{1}{c}{ Measures of Outcomes } & $\begin{array}{c}\text { General } \\
\text { Population }\end{array}$ & $\begin{array}{c}\text { Classified as } \\
\text { Disabled }\end{array}$ & $\begin{array}{c}\text { Classified } \\
\text { Autism Only }\end{array}$ \\
\hline Even enrolled in post-secondary education & $67 \%$ & $60 \%$ & $43.90 \%$ \\
Completed post-secondary education & $52 \%$ & $41 \%$ & $38.80 \%$ \\
At least one paid job 8 years after graduating & $98.6 \%$ & $91 \%$ & $63.20 \%$ \\
Average Hourly Earnings & $\$ 11.40$ & $\$ 10.40$ & $\$ 9.20$ \\
Live independently & $59 \%$ & $49 \%$ & $17 \%$ \\
\hline
\end{tabular}

Two studies use the NLS2 data to test statistical differences between outcomes for those with autism and individuals with other special education classifications. ${ }^{16}$ They also tested the significance of factors that may predict lower outcomes for those with autism. ${ }^{17}$ One study found that individuals with autism are significantly less likely than three comparison groups (individuals with speech and language, learning, and intellectual challenges) to engage in post-secondary education and secure paid employment. ${ }^{18}$ This study also found that higher household incomes, more years since high school, and higher functional skills levels correlated significantly with individuals with autism obtaining post-secondary education and a paying job. ${ }^{19}$ The second study found that individuals with autism were significantly less likely to secure at least one paying job at least once after leaving high school compared to four other special education classifications (individuals with speech and language, learning, emotional, and intellectual challenges). ${ }^{20}$ This study also found that higher age, income, and functional skills (including conversational) were significantly associated with positive employment outcomes for adults with autism. ${ }^{21}$

The ability to drive is critical to successfully transitioning to adulthood for most individuals. ${ }^{22}$ High-quality public transit is typically only available in major urban areas where housing costs are high. Only $11 \%$ of U.S. adults can use transit regularly. ${ }^{23}$ People with autism are less likely to live in areas with high-quality transit, given their employment and income levels. As a result, like most adults in the U.S., those with autism must drive or be driven to access work, health care, education, healthy food, social activities, and other essential services.

Not surprisingly, people with autism often want to drive. ${ }^{24}$ However, they find it difficult to obtain a driver's license..$^{25} \mathrm{~A}$ recent study that linked 52,000 electronic health records of children born from 1987 to 1995 and New Jersey driver licensing data found that about one-third of people with autism were able to obtain a driver's license. ${ }^{26}$ Another study, which surveyed adults (online convenience sample of 703) with autism through various autism-related organizations in New Jersey (or 2016 New Jersey survey), found that $9.3 \%$ of respondents had a driver's license. ${ }^{27}$ An earlier study by Feeley (or 2010 Feeley et al. survey), which surveyed adults with autism or their parent or caretakers (an online convenience sample of 1,077 with recruitment focused in New Jersey) reported that $24.3 \%$ of respondents, many of whom identified as higher-functioning, said that they primarily drove themselves to activities. ${ }^{28} \mathrm{~A}$ convenience sample collects responses from those who are easy to contact. It is a non-probability/non-random sampling method with limited generalizability to the population of interest. The results from the NLS2 survey showed that 
$33.4 \%$ of young adults with autism had a driver's license. ${ }^{29}$ In sum, the best evidence to date suggests that only one-third of people with autism have a driver's license.

Even when adults with autism have a driver's license, they do not drive themselves frequently. ${ }^{30}$ The 2016 New Jersey survey found that $61.4 \%$ of respondents with a driver's license indicated having driving difficulties. ${ }^{31}$ Moreover, the authors state that " $26.1 \%$ of those with driver's licenses did not drive at all, $19.6 \%$ drove less than once a week, $30.4 \%$ drove once or more a week, and only $23.9 \%$ drove daily." ${ }^{32}$ The survey also asked about modes used by adults with autism within the past three months, and only $3.1 \%$ of respondents indicated that they had driven themselves in a private car. However, only $3.6 \%$ of the respondents had no vehicle available to them, $26.4 \%$ had one, $46.9 \%$ had two, and $23.1 \%$ had three or more. ${ }^{33}$

Studies indicate that the most common way adults with autism get to activities is by having their parents drive them. In the 2010 Feeley et al. survey, $70 \%$ of respondents indicated that the primary way they traveled was by having their parents drive them; about $30 \%$ took transit (including public transportation and specialized transit for people with disabilities), and about $14 \%$ were driven in a car by someone else (friends, taxis, and paid providers). ${ }^{34}$ In the 2016 New Jersey survey, about $36 \%$ of respondents were driven by their parents or family within the past three months, $22 \%$ were driven by someone else in a car (friend, volunteer driver, taxi, or ride-hail), $15 \%$ walked, $14 \%$ took transit, and $3.1 \%$ biked. ${ }^{35}$

Even though getting a ride from their parents and family is the most common way adults with autism travel, studies indicate that parents and family members are not able to fully meet travel needs, and providing travel often comes at a cost to family members. ${ }^{36}$ The 2016 New Jersey survey indicated that about $73 \%$ of respondents missed activities because no one was available to provide the ride. ${ }^{37}$ Seventy-three percent of respondents also stated that the people providing them with rides had to forgo their activities, including work, to do so. ${ }^{38}$ Over time, as parents age and die, many adults with autism who do not have the ability or confidence to drive will have few travel resources and options. 


\section{DIAGNOSTIC CHALLENGES AND THEIR POTENTIAL EFFECT ON DRIVING PERFORMANCE}

Adults with autism may face varying degrees of challenges with skills related to executive functioning, social-cognitive perception, motor skills, sensory perception, and sensorymotor integration. ${ }^{39} \mathrm{~A}$ person with autism is clinically identified based on the magnitude of challenges with these skills. Researchers hypothesize that these challenges may also impair driving ability. ${ }^{40}$ See Table 2 for a summary of these skills, general definition, and impact on the driving experience.

Executive functioning is required to manage complex tasks or goals by accurately collecting task-or goal-related information and adapting to changing conditions. ${ }^{41}$ To arrive safely at a destination, drivers must monitor and focus on the road ahead and adjust to changes in roadway conditions. Executive functioning challenges are not just experienced by people with autism but also by teenagers, older people, and those with other types of cognitive and physical impairments. ${ }^{42}$ Teenagers develop executive functioning skills as the frontal lobe of their brain matures into early adulthood. ${ }^{43}$ During this time, vehicle collisions tend to decline and plateau at the age of $25 .{ }^{44}$ The review in this section includes the four elements of executive functioning-working memory, inhibitory control, cognitive flexibility, and emotion regulation - that are identified most frequently in the literature on autism and driving.

Working memory is the capacity to monitor, update, and manipulate visual, auditory, and spatial information in real-time. Drivers must collect a high volume and quality of information about traffic, road, and other external conditions from moment to moment to make good driving decisions. Research suggests that it is challenging for individuals with autism to process objects in motion. ${ }^{45}$ However, this information is often required to identify roadway hazards, ${ }^{46}$ maintain lane position, park, merge into traffic, and make left-hand turns at intersections without signals.

Inhibitory control is the capacity to selectively attend to the relevant task-or goal-related information and ignore irrelevant or distracting information. This capability allows drivers to focus on information critical to the task of driving (i.e., the road ahead and traffic) and filter non-critical information, such as in-car technology, passenger discussions, and external sources (e.g., billboards). ${ }^{47}$

Cognitive flexibility skills provide the ability to adapt to changing goals or task demands. This set of capabilities allows for the use of critical information that drivers hold in working memory to adjust to the ever-changing needs of the driving situation. It includes the situational adaption involved in regulating speeds and other responses to road hazards that are not governed by specific rules or instructions. ${ }^{48}$ Those without this capability may adopt a slow or cautious driving style, which can be hazardous. ${ }^{49}$ People with autism may be more likely than the general population to follow traffic rules and regulations, which could lead to fewer accidents. On the other hand, an inability to flexibly apply rules in different contexts could lead to more accidents. ${ }^{50}$ In general, challenges in this area may make navigation difficult for those with autism. ${ }^{51}$ 
Emotion regulation skills afford the ability to control emotional responses to sensory information. Difficulties in this area may reduce a driver's ability to manage frustration and anxiety while driving. Heightened anxiety can interfere with executive functioning and lead to driving errors. Difficulty processing sensory information can also lead to emotional dysregulation. ${ }^{52}$

Social-cognitive skills include the ability to understand and predict other people's thoughts and actions and include verbal and non-verbal communication. This set of capabilities is necessary to identify driving hazards that are, by nature, social: for example, predicting the actions of other drivers, pedestrians, and bicyclists, and interacting and communicating with them (e.g., through gestures and signals). ${ }^{53}$

The ability to act on information relies on motor skills, or the ability to control the movements of more than one part of the body to perform a specific act, including fine and gross motor skills. The physical ability to adequately perceive visual, auditory, and tactile stimulation must be integrated with motor skills to execute the desired outcome. For example, these skills may include gathering visual and auditory information, turning the steering wheel, pressing on the gas pedal and brake, and shifting gears. 


\section{Table 2. Autism Diagnostic Factors, General Lay Definition, and Application to Driving}

\begin{tabular}{|c|c|c|}
\hline Factors & Definition & Driving \\
\hline $\begin{array}{l}\text { Executive } \\
\text { Functioning (EF) }\end{array}$ & $\begin{array}{l}\text { Manage complex tasks/goals } \\
\text { by accurately collecting related } \\
\text { information and adapting to change. }\end{array}$ & $\begin{array}{l}\text { Monitor and focus on the road ahead and } \\
\text { adapt to evolving roadway conditions. }\end{array}$ \\
\hline $\begin{array}{l}\text { EF- Working } \\
\text { Memory }\end{array}$ & $\begin{array}{l}\text { Monitor, update, and manipulate visual, } \\
\text { auditory, and spatial information. }\end{array}$ & $\begin{array}{l}\text { Collection of a high volume and quality of } \\
\text { information about traffic, road, and other } \\
\text { external conditions in-real time. }\end{array}$ \\
\hline $\begin{array}{l}\text { EF- Inhibitory } \\
\text { Control }\end{array}$ & $\begin{array}{l}\text { Selectively attend to relevant task/ } \\
\text { goal-related information and ignore } \\
\text { irrelevant or distracting information. }\end{array}$ & $\begin{array}{l}\text { Use of critical information held in working } \\
\text { memory to adapt to the ever-changing } \\
\text { demands of the driving situation. }\end{array}$ \\
\hline $\begin{array}{l}\text { EF-Cognitive } \\
\text { Flexibility }\end{array}$ & $\begin{array}{l}\text { Understand and predict other people's } \\
\text { thoughts and actions, including verbal } \\
\text { and non-verbal communication. }\end{array}$ & $\begin{array}{l}\text { Predicting the actions of other drivers, } \\
\text { pedestrians, and bicyclists, and interacting } \\
\text { and communicating with them (e.g., through } \\
\text { gestures and signals). }\end{array}$ \\
\hline $\begin{array}{l}\text { EF-Emotion } \\
\text { Regulation }\end{array}$ & $\begin{array}{l}\text { Control emotional responses to } \\
\text { sensory information. }\end{array}$ & $\begin{array}{l}\text { Difficulties may reduce a driver's ability } \\
\text { to manage frustration and anxiety while } \\
\text { driving. Heightened anxiety can interfere } \\
\text { with executive functioning overall and lead to } \\
\text { driving errors. }\end{array}$ \\
\hline $\begin{array}{l}\text { Social-Cognitive } \\
\text { Perception }\end{array}$ & $\begin{array}{l}\text { Understand and predict other people's } \\
\text { thoughts and actions and include } \\
\text { verbal and non-verbal communication. } \\
\text { Difficulty processing sensory } \\
\text { information can also lead to emotional } \\
\text { dysregulation. }\end{array}$ & $\begin{array}{l}\text { Necessary to identify driving hazards that } \\
\text { are, by nature, social: for example, predicting } \\
\text { the actions of other drivers, pedestrians, and } \\
\text { bicyclists, and interacting and communicating } \\
\text { with them (e.g., through gestures and } \\
\text { signals). }\end{array}$ \\
\hline $\begin{array}{l}\text { Sensory-Motor } \\
\text { Skills and } \\
\text { Integration }\end{array}$ & $\begin{array}{l}\text { Perceive visual, auditory, and tactile } \\
\text { stimulation. Control the movements } \\
\text { of more than one part of the body to } \\
\text { perform a specific act. Integration to } \\
\text { execute the desired outcome. }\end{array}$ & $\begin{array}{l}\text { Gather visual and auditory information, } \\
\text { turning the steering wheel, pressing on the } \\
\text { gas pedal and brake, and shifting gears. }\end{array}$ \\
\hline
\end{tabular}




\section{LITERATURE REVIEW OF THE EVIDENCE LINKING FACTORS ASSOCIATED WITH AUTISM TO DRIVING PERFORMANCE}

This section reviews the peer-reviewed research that examines the relationship between driving performance and common challenges faced by individuals with autism, as described in the previous section. The literature is critically reviewed and summarized in chronological order. See also Table 3 for a description of these studies.

Sheppard et al. explored the impact of social and cognitive challenges on roadway hazard identification. ${ }^{54}$ The study included 44 young (ages 16-24) adult males with $(n=23)$ and without autism $(n=21)$ who did not have a driver's license. The study recruited participants from academic and vocational college courses in England; however, the specific methods of recruitment are not described, except that the recruitment was base on driving challenges. The two groups had similar ages and intelligence quotient (IQ) scores (verbal, performance, and full scale) and had significantly different scores on the autism quotient (AQ) test, ${ }^{55}$ which measures the strength of features associated with autism. The participants watched ten driving video simulation clips, of which five included a person who is the source of the hazard (i.e., pedestrian and cyclist) and five included a vehicle that is the source of the hazard (i.e., car, van, and bus reversing or pulling out into the road). Researchers asked participants to press a response key as soon as they identified the developing hazard. The statistical analysis of the between-group test performances indicated that the autism group, compared to the non-autism group, identified significantly $(p<0.05)$ fewer social hazards and were slower to respond to social hazards. Some of the limitations to this study are that responses to simulated hazards may not replicate responses to hazards in realworld situations and that the small sample size and methods of recruitment used in the study limit the generalizability of the findings to autism and non-autism populations.

Classen et al. explored the differences between adolescent non-drivers with $(n=7)$ and without autism $(n=22)$ in their performance on simulated driving tests and standardized tests of executive functioning and motor skills. ${ }^{56}$ The study included participants in the community who were conveniently available to participate in the study. The autism and nonautism groups were not significantly different for age, gender, ethnicity, race, education, or history of physical and speech therapy. However, there was a significant difference in the history of occupational therapy interventions. The following tests of executive functioning and motor skills were administered to both groups by an occupational therapist certified for driving rehabilitation (OT-DRS): Visual Analyzer Tests, Useful Field of View, Comprehensive Trail Making Tests, Beery Visual Motor Integration Test, Symbol Digit Modality Test, and Bruininks-Oseretsky Test. The results indicated significantly weaker performance on tests in the autism group relative to the non-autism group for right eye visual acuity, cognitive flexibility, inhibitory control, visual-motor integration (i.e., effective communication between visual information and motor action), and general motor performance.

Classen et al. accessed participants' driving skills with a driving simulator (STISM M500W).

57 The results indicated significantly weaker performance on tests in the autism group relative to the non-autism group for driving skills related to operating a vehicle (accelerator, brake, steering, and turn signals), visual scanning (i.e., ability to accurately perceive visual 
information), speed regulation, lane maintenance, vehicle positioning, and adjustment to stimulation. Also, the non-autism group had significantly more traffic light tickets. Like the previous study, the limitations of Classen et al. include simulated versus real-world assessment of driving skills. ${ }^{58}$ The small sample size and recruitment methods limit the generalizability of the findings. The study does not include a discussion of power statistics, and thus, the analysis may have failed to detect some executive functioning and motor challenges. Statistical power refers to the probability of detecting an effect if there is onet to detect. Power analysis refers to the minimum sample size required to detect an effect in the sample.

Chee et al. assessed the beliefs and attitudes toward driving with a convenience sample of young adult drivers and non-drivers with $(n=50)$ and without autism $(n=57) .{ }^{59}$ The study included participants with autism if they met the Diagnostic and Statistical Manual of Mental Disorders, $4^{\text {th }}$ edition (DSM-IV) criteria for autism and had an IQ score equal to or greater than 85. The authors implemented the Q-methodology with this sample to develop and identify driving-related Q-statements and then sorted the statements in order of importance by driving status (learner, learning permit, and licensed) for both autism and non-autism groups. The results were then statistically analyzed using factor analysis with qualitative interpretations of the factors. The results indicated that anxiety or emotion regulation posed a significant barrier to driving for those with autism. This study suffers from limitations due to generalizability, uncertainties about the ability of the Q-statements to measure actual driving attributes and beliefs, adequacy of the sorting categories to control for confounding factors, and the absence of a discussion of the power of the analysis to detect significant group differences.

Daily et al. examined differences in driving behavior, preferences, and performance by administering online surveys that solicit anonymous self-reported responses from adult drivers (ages 18-60) with a driver's license with $(n=78)$ and without autism $(n=94) \cdot{ }^{60}$ These surveys included a driving history and preferences questionnaire and a validated Driving Behavior Questionnaire (DBQ). Participants anonymously completed these surveys on-line. The study recruited participants with autism from an autism support website and recruited participants without autism from an existing database of adult drivers. The study excluded participants who reported a history of developmental disabilities or neurological conditions that could impact driving. The authors conducted statistical analyses of between-group differences and found that the autism group, compared to the non-autism group, averaged a two-year delay in obtaining a license and drove one less day a week on average. They were also more likely to place restrictions on their driving voluntarily (i.e., avoiding heavy traffic, evening and night driving, and highways), rate driving skills lower, and have a traffic violation within the last two years. There are several limitations in the study, including the use of an online convenience sample. Also, self-reported responses may be unreliable in general. Finally, the lack of between-group controls may confound the results.

Ross et al. analyzed the effectiveness of driving instruction methods and the effects of executive function skills (specifically, inhibitory control, cognitive flexibility, and emotion regulation), social cognition, and motor planning on driving performance by surveying driving instructors $(n=52)$ with experience teaching people with autism to drive.$^{61}$ The study recruited participants from driving schools in Flanders; the sample included 144 instructors, 
98 of whom completed the survey (68\% response rate). The final study sample included $50 \%$ of the 98 respondents who had experience teaching autism students. The authors analyzed the results of the open-ended survey questions using content analysis procedures and assessed the closed-ended survey questions with summary statistics. For driving instructions, the analysis of open-ended questions suggested a "need for structure, clarity, visual demonstration, practice and repetition, and individualize approach." ${ }^{2}$ For the closedended questions, all tested challenges ranked above average for impact on driving: inhibitory control (i.e., multitasking and concentration/attention), cognitive flexibility (i.e., generalizing information, route changes, and rule-breaking), social cognition (i.e., judging other people's behavior), emotion regulation, and motor planning. Limitations of this study include small sample size and no tests of statistical significance, no verification that instructor's perceptions and assessments reflect actual cause and effect relationships examined in the study, and poor documentation of the survey instruments or limited survey questions.

Cox et al. tested the relationships among executive functioning (i.e., inhibitory control, cognitive flexibility, and working memory), driving motor skills, and driving performance as measured by driving simulator (Driver Guidance System or DGS-78) tests administered to males (ages 15 to 23), 17 of whom had autism and a driving learner's permit and 27 of whom did not have autism but had a recently obtained driver's license. ${ }^{63}$ The authors report that the driving simulator's operational tests mirror neuropsychological tests for executive functioning skills, and tactical tests monitor 31 driving performance variables that significantly predict on-road driving performance. The authors recruited the autism sample from a driver training study and the non-autism sample from another study of adolescents who had recently obtained their driver's license. The study excluded those with a brain injury; intellectual disability; genetic or chromosomal disorder; severe physical, medical, or psychiatric condition that impairs driving ability; and those who required adaptive equipment to drive. Inclusion in the autism group required a parent-reported diagnosis and subsequent parent responses to standardized autism assessments. There was no significant difference between the groups for ethnicity, but the autism group was older than the non-autism group. The authors statistically analyzed between-group differences in the test results and found that the autism group performed worse than the control group for:

- Basic motor skills: steering (hand/arm) $(p<001)$, but not braking (foot/leg) $(p=0.14)$ or combined steering/braking $(p=0.25)$;

- Tactical driving performance $(p=0.0009)$ : attributed to bumping lead car and increased swerving (lane positioning) and lane changes; and

- Executive functioning: working memory and cognitive flexibility, but not inhibitory control.

They found that layering an additional working memory task onto a complex driving task increased steering/braking errors and reduced working memory performance in the autism group compared to the control. Working memory challenges in the autism group may explain some of the hand/arm steering errors. Finally, visual-motor integration challenges as operationalized by hand-eye for steering and foot-eye for braking did not significantly impact performance. 
Weaknesses of the Cox et al. study include simulated versus real-world assessment of driving skills, limited generalizability due to small sample size and methods of recruitment (i.e., only men and convenience sampling), use of parent reports of autism symptoms rather than clinician measurement, limited group matching (e.g., demographic and intellectual attributes), and no discussion of power statistics. ${ }^{64}$ Also, the study did not test all hypothesized challenges to performance (e.g., anxiety, social-cognitive, and visual field monitoring), and thus, there is potential for a confounded analysis.

Sheppard et al. tested whether judging the location of moving objects in a driving context is a more significant challenge for those with autism compared to those without autism. ${ }^{65}$ The study included 44 adult males without a driver's license enrolled in academic or vocational courses, 23 with autism, and 21 without autism. The study recruited participants from colleges in England enrolled in academic or vocational courses. The study did not recruit participants because they had a driving challenge and excluded participants with a visual or motor impairment. The authors matched the autism and non-autism groups' age and IQ scores (verbal, performance, and full scale). The authors administered the IQ and Autism Quotient (AQ) tests to all participants for purposes of group classification.

The authors presented visual driving sequences to each participant with an Apple (Powerbook) laptop and then asked participants questions about the sequences (48 trials for each respondent), which simulated self-motion towards a junction while another car approaches from a side road. The sequences differed in four ways: (1) by the other car's approach angle (obtuse and perpendicular), (2) the self-motion trajectory (straight and curved), (3) the other car's arrival time (before and after), and (4) junction local cue (reference point present and absent). The sequences end before the cars reach the junction, and participants decide which car would be the first to reach the intersection. Sixteen sequences were administered three times to each participant for a total of 48 trials. The authors used a mixed design statistical analysis $(2 \times 2 \times 2 \times 2)$ to evaluate the results. The only significant difference between the autism group and the non-autism group was that the autism group had significantly more errors than the non-autism group for the straight trajectory and not for the curved trajectory. All other effects and interactions were not significant. The authors suggested that future research should explore the interaction between eye-tracking, patterns of attention, and driving performance on straight roads. The study used a convenience sample and thus likely lacks generalizability. Also, the study uses simulated driving, which may not accurately represent performance under real driving conditions.

Chee et al. evaluate the real-world driving performance of 27 adult drivers (ages 1849), 16 with and 21 without autism, and the contribution of cognitive and visual-motor challenges to performance. ${ }^{66}$ The study uses a convenience sample with participants recruited by flyers, advertisements, and on-line registration databases. The study included autism participants with a self-reported autism diagnosis, the ability to communicate and understand English, at least 20/40 visual acuity (Meter 2000 Series Revised ETDRS chart), a current valid driver's license, access to an insured vehicle, and no diagnosis of a co-morbid intellectual disability. The study excluded non-autism participants with selfreported pre-existing physical, visual, or cognitive impairments impacting driving. The study matched autism and non-autism groups on age, gender, driving experience, and hours of 
driving (per week). Classification into autism and non-autism groups uses the results of the $A Q$ test administered to all participants. The study operationalized driving experience as a novice ( $<2$ years of driving experience) or experienced ( $\geq 2$ years of driving experience).

The Chee et al. study assessed cognitive and visual-motor challenges by administering the following tests to all participants: ${ }^{67}$

- Useful Field of View Test (UFOV) to measure visual perception, cognitive flexibility, and inhibitory control;

- Balloon Analog Risk Task (BART) to measure risk-taking tendency;

- Delis-Kaplan Executive Function System (D-KEFS) for executive function; and

- Block Design (BD) test and Benton Judgment of Line Orientation Test (BJLOT) for visual-spatial perception.

Participants completed a standardized on-road route with their vehicle, which took about 25 minutes. The route included one lane-merging traffic scenario, seven roundabouts, three right turns, two left turns, two traffic light intersections, and three pedestrian crossings. An observer sat in the back and completed two standard assessment of driving performance (i.e., driving performance checklist or DPC and performance analysis of driving ability or P-Drive). The authors performed statistical analyses of between-group differences, which included power statistics. They also conducted a univariate regression of the cognitive and visual-motor challenges experienced by the autism group against driving performance. Compared to the non-autism group, the autism group scored significantly worse on motor speed and visual scanning on the cognitive and visual-motor tests. They also performed significantly worse on vehicle maneuvering (e.g., steering at intersections observed to be more hesitant and slower, especially at right turns) and better on roundabouts and traffic lights due to better rule-following behavior. These results had $80 \%$ power and 0.95 standard difference. The univariate regression analysis indicated that age, response inhibition, and risk-taking were positively associated with lower driving performance. The limitations of this study include generalizability (sample size and recruitment). There are also some issues related to the assessor, which include potential bias because they knew participants' diagnoses. Further, driving conditions could have varied (from less to more difficult) for participants because assessments took place at different times of day, with different weather conditions, and unexpected roadway construction projects on the route.

Reimer et al. explored the interaction of driving performance, inhibitory control (visual attention), cognitive flexibility, and emotion regulation with data from driving simulation scenarios in which 20 driving men (ages 18 to 24) participated, half with and half without autism. ${ }^{68}$ The study recruited people with autism from the outpatient population in the Bressler Clinical and Research Program for Autism at the Massachusetts General Hospital and non-autism participants from a sample of 75 participants in a concurrent study at Massachusetts Institute of Technology. The inclusion criteria for autism participants were a DSM-IV autism diagnosis, gender, IQ $\geq 85$, driver's licenses, no major sensorimotor challenges (e.g., deafness, blindness), and ability to understand and speak English. For 
non-autism participants, the criteria were availability of eye-tracking measurements and age-and gender-matched to autism participants. Statistics conducted after data collection indicated that the groups also matched on IQ, driving activity, and cell phone performance.

The driving simulation (STISIM Drive version 2.08.02) in Reimer et al. included a mix of driving environments considered stimulating (traffic on an urban road), moderately demanding (rural and highway), and monotonous (a straight road with little traffic). 69 The scenario introduced mobile phone tasks during the urban road portion of the scenarios with increasing complexity to increase the cognitive and attentional demands on the driver. During the simulation, the study monitored the heart rate as an indicator of anxiety or emotion regulation and eye-tracking as an indicator of visual attention (or inhibitory control). The changes introduced by driving and mobile phone task complexity tested cognitive flexibility. The statistical analysis of between-group results of the driving simulation scenario found no statistical difference between the driving performance of autism and non-autism participants. The results indicated a somewhat elevated heart rate throughout the simulation for autism participants compared to non-autism participants, but the differences were not statistically significant. However, the analysis did find statistically significant differences in horizontal and vertical gaze patterns between the two groups. The autism group responded to greater cognitive demands by shifting visual attention away from the road ahead and towards less complex areas of the visual field, which may make it difficult for those with autism to respond to hazard events and drive safely. The small sample size and convenience sampling limit the generalizability to the general population of those with and without autism. Most studies do not discuss the power of their statistical analysis and thus its ability to find an effect if there is one. 
Table 3. Summary of Studies on Driving Performance and Causal Factors for Individuals with Autism

\begin{tabular}{|c|c|c|c|c|c|c|c|c|}
\hline $\begin{array}{l}\text { Authors, } \\
\text { Year } \\
\text { (country) }\end{array}$ & Challenges & Sample & Recruitment & $\begin{array}{l}\text { Inclusion (I) and } \\
\text { Exclusion (E) } \\
\text { Criteria }\end{array}$ & $\begin{array}{l}\text { Between-Group } \\
\text { Controls }\end{array}$ & Instruments & Data Analysis & Key Findings for Autism \\
\hline $\begin{array}{l}\text { Sheppard } \\
\text { et al., } \\
2009 \text { (UK) }\end{array}$ & & $\begin{array}{l}\text { Young adult } \\
\text { males w/o } \\
\text { driver's } \\
\text { license: } n=13 \\
\text { autism \& } \\
n=21 \text { non- } \\
\text { autism }\end{array}$ & Convenience & $\begin{array}{l}\text { E: visual, motor, } \\
\text { or other comorbid } \\
\text { impairment }\end{array}$ & $\begin{array}{l}\text { Match: age, IQ; } \\
\text { Differ: AQ (autism } \\
\text { quotient) }\end{array}$ & $\begin{array}{l}\text { Simulated road hazard } \\
\text { n videos: } 5 \text { social \& } 5 \\
\text { non-social }\end{array}$ & $\begin{array}{l}\text { Statistical tests } \\
\text { BGD (between- } \\
\text { group difference) }\end{array}$ & $\begin{array}{l}\text { Identified significantly fewer } \\
\text { social hazards \& at a slower } \\
\text { rate }\end{array}$ \\
\hline $\begin{array}{l}\text { Classen et } \\
\text { al., } 2013 \\
\text { (U.S.) }\end{array}$ & $\begin{array}{l}\text { Executive } \\
\text { functioning, motor, } \\
\text { driving skills }\end{array}$ & $\begin{array}{l}\text { Adolescents } \\
\text { w/o learners } \\
\text { permit or } \\
\text { driver's } \\
\text { license: } n=7 \\
\text { autism \& } \\
\text { n=22 non- } \\
\text { autism }\end{array}$ & Convenience & $\begin{array}{l}\text { E: seizures, } \\
\text { below minimum } \\
\text { visual acuity, } \\
\text { severe psychiatric } \\
\text { condition; I: English } \\
\text { communication }\end{array}$ & $\begin{array}{l}\text { Match: age, } \\
\text { gender, ethnicity, } \\
\text { race, education, } \\
\text { physical \& speech } \\
\text { therapy; Differ: } \\
\text { occupational } \\
\text { therapy }\end{array}$ & $\begin{array}{l}\text { Driving simulator } \\
\text { for driving skills; } \\
\text { standardized tests of } \\
\text { hexecutive function \& } \\
\text { motor skills }\end{array}$ & $\begin{array}{l}\text { Statistical tests } \\
\text { BGD }\end{array}$ & $\begin{array}{l}\text { Significantly worse for } \\
\text { executive functioning and } \\
\text { motor skills (i.e., right eye } \\
\text { visual acuity, cognitive } \\
\text { flexibility, inhibitory control, } \\
\text { visual-motor integration) } \\
\text { \& driving skills for vehicle } \\
\text { operations, visual scanning, } \\
\text { speed regulation, lane } \\
\text { maintenance, vehicle } \\
\text { positioning, adjustment to } \\
\text { stimulation, \& traffic light } \\
\text { tickets }\end{array}$ \\
\hline $\begin{array}{l}\text { Chee et } \\
\text { al., } 2014 \\
(A U)\end{array}$ & $\begin{array}{l}\text { Driving perceptions/ } \\
\text { attitudes }\end{array}$ & $\begin{array}{l}\text { Young } \\
\text { adults with } \\
\text { w/o license: } \\
n=50 \text { autism } \\
I Q=\geq 85 \& \\
n=57 \text { non- } \\
\text { autism }\end{array}$ & Convenience & $\begin{array}{l}\text { I: DSM-IV for } \\
\text { autism, English } \\
\text { communication, } \\
\text { driving status }\end{array}$ & $\begin{array}{l}\text { Differ: age, } \\
\text { gender, driving } \\
\text { status (Q-studies } \\
\text { require variation } \\
\text { and sorting by } \\
\text { gender \& driver } \\
\text { status) }\end{array}$ & $\begin{array}{l}\text { Q methodology to } \\
\text { identify \& categorize } \\
\text { viewpoints of autism \& } \\
\text { non-autism groups }\end{array}$ & Factor analysis & $\begin{array}{l}\text { Anxiety or emotion } \\
\text { regulation: important } \\
\text { barriers }\end{array}$ \\
\hline $\begin{array}{l}\text { Daly et } \\
\text { al., } 2014 \\
\text { (U.S.) }\end{array}$ & $\begin{array}{l}\text { Driving history, } \\
\text { behavior, } \\
\text { performance }\end{array}$ & $\begin{array}{l}\text { Adult drivers } \\
\text { with license: } \\
n=78 \text { autism } \\
\& n=94 \text { non- } \\
\text { autism }\end{array}$ & Convenience & $\begin{array}{l}\text { E: Developmental } \\
\text { disabilities or } \\
\text { neurological } \\
\text { conditions impact } \\
\text { driving }\end{array}$ & $\begin{array}{l}\text { Differ: gender, } \\
\text { ethnicity, } \\
\text { education, and } \\
\text { autism }\end{array}$ & $\begin{array}{l}\text { Driving history \& } \\
\text { preferences survey by } \\
\text { authors and validated } \\
\text { Driving Behavior } \\
\text { Questionnaire }\end{array}$ & $\begin{array}{l}\text { Statistical tests } \\
\text { BGD }\end{array}$ & $\begin{array}{l}\text { An average } 2 \text {-year delay in } \\
\text { licensure \& drive } 1 \text { less day/ } \\
\text { week; restrict driving; rate } \\
\text { driving skills lower; traffic } \\
\text { violation w/i } 2 \text { years; more } \\
\text { problem driving behaviors; } \\
\text { higher driving risk scores }\end{array}$ \\
\hline
\end{tabular}




\begin{tabular}{|c|c|c|c|c|c|c|c|c|}
\hline $\begin{array}{c}\text { Authors, } \\
\text { Year } \\
\text { (country) }\end{array}$ & Challenges & Sample & Recruitment & $\begin{array}{c}\text { Inclusion (I) and } \\
\text { Exclusion (E) } \\
\text { Criteria }\end{array}$ & $\begin{array}{c}\text { Between-Group } \\
\text { Controls }\end{array}$ & Instruments & Data Analysis & Key Findings for Autism \\
\hline $\begin{array}{l}\text { Ross et } \\
\text { al., } 2015 \\
(\mathrm{BE})\end{array}$ & $\begin{array}{l}\text { Inhibitory control, } \\
\text { cognitive flexibility, } \\
\text { emotion regulation, } \\
\text { social-cognitive, } \\
\text { motor planning }\end{array}$ & $\begin{array}{l}\mathrm{n}=52 \text { driving } \\
\text { instructors }\end{array}$ & $\begin{array}{l}\text { Instructors from } \\
\text { all area diving } \\
\text { schools }\end{array}$ & Not applicable & Not applicable & $\begin{array}{l}\text { Open-ended survey } \\
\text { questions on driving } \\
\text { instructions; Closed } \\
\text { survey on the impact of } \\
\text { autism challenges on } \\
\text { driving performance }\end{array}$ & $\begin{array}{l}\text { Content analysis } \\
\text { \& summary } \\
\text { statistics }\end{array}$ & $\begin{array}{l}\text { For driving instructions: } \\
\text { "need for structure, clarity, } \\
\text { visual demonstration, } \\
\text { practice and repetition, and } \\
\text { individualize approach." } \\
\text { Driving impact: ranked } \\
\text { above average for inhibitory } \\
\text { control, cognitive flexibility, } \\
\text { social cognition, emotion } \\
\text { regulation, \& motor planning }\end{array}$ \\
\hline $\begin{array}{l}\text { Cox et } \\
\text { al., } 2016 \\
\text { (U.S.) }\end{array}$ & $\begin{array}{l}\text { Inhibitory control, } \\
\text { cognitive flexibility, } \\
\text { working memory, } \\
\text { motor skills, driving } \\
\text { performance }\end{array}$ & $\begin{array}{l}\text { Males (ages } \\
\text { 15-23): } n=17 \\
\text { autism with } \\
\text { learner's } \\
\text { permit \& } n=27 \\
\text { non-autism } \\
\text { recent driver's } \\
\text { license }\end{array}$ & $\begin{array}{l}\text { Convenience } \\
7 \\
6\end{array}$ & $\begin{array}{l}\text { E: brain injury, } \\
\text { intellectual } \\
\text { disability, genetic } \\
\text { or chromosomal } \\
\text { disorder, severe } \\
\text { physical, medical or } \\
\text { psychiatric condition } \\
\text { impairs driving, } \\
\text { require adaptive } \\
\text { driving equipment; I: } \\
\text { parent report autism } \\
\text { diagnosis }\end{array}$ & $\begin{array}{l}\text { Match: ethnicity; } \\
\text { Differ: age, driver } \\
\text { status }\end{array}$ & $\begin{array}{l}\text { Driving simulator tests } \\
\text { operational driving for } \\
\text { motor tasks \& inhibitory } \\
\text { control, cognitive } \\
\text { flexibility, working } \\
\text { memory \& tactical } \\
\text { driving by monitoring } 31 \\
\text { variables predict driving } \\
\text { performance }\end{array}$ & $\begin{array}{l}\text { Statistical tests } \\
\text { BGD }\end{array}$ & $\begin{array}{l}\text { Significantly worse: basic } \\
\text { motor skills for steering } \\
\text { (hand/arm) but not braking } \\
\text { (foot/leg) or combined } \\
\text { steering/braking; tactical } \\
\text { driving performance: } \\
\text { bumping lead car \& } \\
\text { increased swerving (lane } \\
\text { positioning) \& lane changes } \\
\text { executive functioning: } \\
\text { working memory and } \\
\text { cognitive flexibility, but not } \\
\text { inhibitory control. Visual- } \\
\text { motor integration (i.e., } \\
\text { hand-eye for steering and } \\
\text { foot-eye for braking) non- } \\
\text { significant }\end{array}$ \\
\hline
\end{tabular}




\begin{tabular}{|c|c|c|c|c|c|c|c|c|}
\hline $\begin{array}{l}\text { Authors, } \\
\text { Year } \\
\text { (country) }\end{array}$ & Challenges & Sample & Recruitment & $\begin{array}{l}\text { Inclusion (I) and } \\
\text { Exclusion (E) } \\
\text { Criteria }\end{array}$ & $\begin{array}{c}\text { Between-Group } \\
\text { Controls }\end{array}$ & Instruments & Data Analysis & Key Findings for Autism \\
\hline $\begin{array}{l}\text { Sheppard } \\
\text { et al., } \\
2016 \text { (UK) }\end{array}$ & Visual perception & $\begin{array}{l}\text { Adult males } \\
\text { without } \\
\text { driver's } \\
\text { license: } n=23 \\
\text { autism \& } \\
n=21 \text { non- } \\
\text { autism }\end{array}$ & Convenience & $\begin{array}{l}\text { E: Visual or motor } \\
\text { impairment }\end{array}$ & $\begin{array}{l}\text { Match: age, IQ; } \\
\text { Differ: } A Q\end{array}$ & $\begin{array}{l}\text { Simulated driving } \\
\text { sequences: self-motion } \\
\text { towards junction while } \\
\text { other car approaches } \\
\text { from side road \& ends } \\
\text { before cars reach } \\
\text { junction, which differ } \\
\text { by car approach angle, } \\
\text { self-motion trajectory, } \\
\text { car arrival time, \& } \\
\text { junction local cue }\end{array}$ & $\begin{array}{l}\text { Mixed design } \\
\text { Statistical tests }\end{array}$ & $\begin{array}{l}\text { Significantly more errors for } \\
\text { straight trajectory but not } \\
\text { curved }\end{array}$ \\
\hline $\begin{array}{l}\text { Chee et } \\
\text { al., } 2017 \\
(A U)\end{array}$ & $\begin{array}{l}\text { Inhibitory control, } \\
\text { driving performance }\end{array}$ & $\begin{array}{l}\text { Adult drivers } \\
\text { (age 18-49): } \\
n=16 \text { autism } \\
\& n=21 \text { non- } \\
\text { autism }\end{array}$ & Convenience & $\begin{array}{l}\text { autism I: self- } \\
\text { report autism } \\
\text { diagnosis, English } \\
\text { communication, at } \\
\text { least } 20 / 40 \text { visual } \\
\text { acuity, driver's } \\
\text { license, insured } \\
\text { vehicle, no comorbid } \\
\text { intellectual disability; } \\
\text { Non-autism E: } \\
\text { self-report physical, } \\
\text { visual, or cognitive } \\
\text { impairments }\end{array}$ & $\begin{array}{l}\text { Match: age, } \\
\text { gender, driving } \\
\text { experience; } \\
\text { Differ: AQ } \\
\end{array}$ & $\begin{array}{l}\text { Standard cognitive \& } \\
\text { visual-motor tests. } \\
\text { Driving performance: } \\
\text { On-road route with own } \\
\text { vehicle ( } 25 \text { min) and } \\
\text { in-vehicle observer } \\
\text { completing standard } \\
\text { assessments of driver } \\
\text { performance }\end{array}$ & $\begin{array}{l}\text { Statistical tests } \\
\text { BGD, power } \\
\text { statistics, and } \\
\text { univariate } \\
\text { regression }\end{array}$ & $\begin{array}{l}\text { Significantly worse on motor } \\
\text { speed \& visual scanning, } \\
\text { but better on roundabouts } \\
\& \text { traffic lights. } 80 \% \text { power } \\
\& 0.95 \text { SD; greater age, } \\
\text { response inhibition, and } \\
\text { risk-taking score significantly } \\
\text { related to lower driving } \\
\text { performance }\end{array}$ \\
\hline
\end{tabular}


Authors,

\section{Year}

\section{Challenges}

Sample

Recruitment

Inclusion (I) and

(country)

Reimer et Inhibitory control, Driving males Convenience

al., 2018 cognitive flexibility, (ages 18-24):

(U.S.) emotion regulation, $n=10$ autism

and driving \& $n=10$ non-

performance autism

$\begin{array}{cc}\begin{array}{c}\text { Exclusion (E) } \\ \text { Criteria }\end{array} & \begin{array}{c}\text { Between-Group } \\ \text { Controls }\end{array}\end{array}$

Instruments

Data Analysis Key Findings for Autism

autism I: autism DSM-IV, male,

minimum IQ 85. I:

driver's license, no

major sensorimotor

challenges, English

communication;

I: eye-tracking

measures available,

matching age \&

gender
Match: gender

(male), age, IQ,

driving activity,

Driving simulation: mix Statistical tests

of driving environments BGD

traffic on urban road,

rural \& highway, \&

straight road with little

traffic with increasingly

complex phone tasks

introduced. Measures

heart rate (emotion

regulation) \& eye-

tracking (inhibitory

control); changes

introduced by driving

and phone task

complexity tests

cognitive flexibility
No significant difference in driving performance; nominally elevated heart rate for autism but not significant; statistical differences in horizontal and vertical gaze patterns: shifted visual attention away from road \& less complex areas of visual field 
To summarize, this section includes a review of the available literature on driving performance and symptoms of autism hypothesized to impact driving performance. These studies were largely exploratory, with results that can only be applied to study participants. Most studies used a convenience sample and included a relatively small number of participants with and without autism (generally, less than 50 total participants). These studies frequently used criteria to exclude challenges (e.g., intelligence, physical, and psychiatric) other than autism that could impair driving skills and confound study results. Studies varied in their between-group controls; that is, most included some demographic factors (e.g., age, gender, ethnicity, and education) and rarely driving status, driving experience, or IQ scores. Many studies used a driving simulator to measure driving performance and/or to test different hypotheses. One study used a real-world driving route. The studies measure performance in a variety of ways, including standardized tests of hypothesized autism challenges, driving performance, and monitoring for physiological responses. Between-group statistical tests were the most common methods of data analysis. Table 4 summarizes the key findings of the literature review.

\section{Table 4. Summary of Study Results by Skill}

\begin{tabular}{|c|c|}
\hline Skill & Driving Impacts \\
\hline \multirow[t]{5}{*}{ Driving Performance } & $\begin{array}{l}\text { - Poorer performance operating a vehicle (accelerator, brake, steering, and turn sig- } \\
\text { nals), speed regulation, lane maintenance, and vehicle positioning }{ }^{70}\end{array}$ \\
\hline & $\begin{array}{l}\text { - Self-reported history of an average two-year delay in obtaining a license, driving one } \\
\text { less day per week on average, self-restricting frequency and types of driving (e.g., } \\
\text { heavy traffic and highways), lower driving skills, and a traffic violation within the last } \\
\text { two years }\end{array}$ \\
\hline & $\begin{array}{l}\text { - More problem driving behaviors and higher driving risk scores from standardized driv- } \\
\text { ing assessment }{ }^{72}\end{array}$ \\
\hline & $\begin{array}{l}\text { - Increase in bumping lead car, swerving (lane positioning), and lane changes from } \\
\text { between-group tests of driving simulation results }{ }^{73}\end{array}$ \\
\hline & - Challenges steering (eye-hand/-arm) ${ }^{74}$ \\
\hline
\end{tabular}

Working Memory

- Adding a working memory task onto a complex driving task increases steering/braking errors and reduces working memory performance from between-group tests of driving simulation results ${ }^{75}$

- Poorer inhibitory control from between-group tests of standardized assessment results $^{76}$

- Above-average inhibitory control rank in a survey of impact on driving performance ${ }^{77}$

- Visual gaze significantly different: in group with autism visual attention shifted away from the road ahead and towards less complex area of the visual field in response to greater cognitive demands ${ }^{78}$

- Response inhibition and risk-taking were positively associated with lower driving performance among those with autism ${ }^{79}$ 


\begin{tabular}{|c|c|}
\hline Skill & Driving Impacts \\
\hline \multirow[t]{5}{*}{ Cognitive flexibility } & $\begin{array}{l}\text { - Poorer cognitive flexibility from between-group tests of standardized assessment } \\
\text { results }^{80}\end{array}$ \\
\hline & - Above-average rank in the survey of impact on driving performance ${ }^{81}$ \\
\hline & - Poorer cognitive flexibility from between-group tests of driving simulation results ${ }^{82}$ \\
\hline & $\begin{array}{l}\text { - Steering at intersections more hesitant and slower, especially at right turns from be- } \\
\text { tween-group tests of driving performance on a real-world driving route }{ }^{83}\end{array}$ \\
\hline & $\begin{array}{l}\text { - Better on roundabouts and traffic lights due to better rule-following behavior from } \\
\text { between-group tests of driving performance on a real-world on-driving route }{ }^{84}\end{array}$ \\
\hline \multirow[t]{2}{*}{ Emotion regulation } & - Anxiety an important barrier to driving (from Q-study analysis ${ }^{85}$ ) \\
\hline & - Above-average rank in a survey of impact on driving performance ${ }^{86}$ \\
\hline \multirow[t]{2}{*}{ Social-Cognitive } & $\begin{array}{l}\text { - Speed and frequency of identifying social hazards from between-group tests of driving } \\
\text { simulation results }{ }^{87}\end{array}$ \\
\hline & - Above-average rank in a survey of impact on driving performance 88 \\
\hline \multirow[t]{3}{*}{ Sensory Perception } & $\begin{array}{l}\text { - Poorer right eye visual acuity from between-group tests of standardized assessment } \\
\text { results }^{89}\end{array}$ \\
\hline & $\begin{array}{l}\text { - Greater visual perceptual errors in a driving simulator when driving along a straight } \\
\text { trajectory from between-group tests of driving simulation results }\end{array}$ \\
\hline & $\begin{array}{l}\text { Poor visual scanning from between-group tests of driving performance on a real-world } \\
\text { on-driving route }{ }^{91}\end{array}$ \\
\hline \multirow[t]{3}{*}{ Sensory-Motor } & $\begin{array}{l}\text { - Poorer visual-motor integration from between-group tests of standardized assessment } \\
\text { results }^{92}\end{array}$ \\
\hline & - Above-average rank in a survey of impact on driving performance ${ }^{93}$ \\
\hline & $\begin{array}{l}\text { Poorer motor speed performance from between-group tests of driving performance on } \\
\text { a real-world on-driving route }{ }^{94}\end{array}$ \\
\hline
\end{tabular}




\section{AUTONOMOUS VEHICLES}

As discussed previously, fully autonomous vehicles promise to address all the driving challenges associated with autism; however, it is unlikely that such vehicles will be publicly available in the foreseeable future because of the very significant technological, infrastructural, and institutional barriers that must be overcome in order to achieve full automation. However, there are promising short-term opportunities that fall short of full vehicle automation that may improve driving performance and transit options for those with autism.

This section summarizes the Society of Automotive Engineers' (SAE) International levels of autonomous vehicles and discusses how each level could practically be used, in the near future, to address the specific driving needs of individuals with autism. SAE levels of automation are the industry standard; the U.S. Department of Transportation and the United Nations have adopted the SAE standards. ${ }^{95}$

Level 0: No Automation. Most of the vehicles on the road today fall into this category because they have no autonomous assistance technologies. The human driver steers the wheel and operates the pedals (acceleration/deceleration and brakes), also negotiating traffic. Level 0 vehicles often include warning systems, which could help reduce driving errors in those with autism. However, such features come with an added cost to the purchase of a vehicle. These features are not considered automation because the warning does not trigger autonomous action by the vehicle. The following are level 0 features that may help drivers with autism.

Blind Spot Monitoring monitors the lanes to the left and right of vehicles, especially the spots over the drivers' shoulders that might be hard to see. If a vehicle enters a driver's blind spot, then the driver is alerted to its presence, often with a light on the outside mirror. If the driver then turns on the lane change signal, a more urgent signal is triggered by the system. This system may help drivers with autism who are more easily distracted. It may also help those with autism feel more confident driving on multi-lane highways. As described above, some research has indicated that drivers with autism restrict highway driving.

Rear Cross-Traffic Alerts warn drivers, with an auditory or visual cue, of traffic approaching from the sides as they reverse their vehicle. Some systems can detect bicycles and pedestrians. These systems are helpful when parked cars might be obstructing a driver's side views. They may also help drivers with autism who find it difficult to judge the trajectory of cross-traffic and thus to assess when it is safe to reverse a vehicle (i.e., drivers with visual perceptual and motor integration challenges).

Adaptive Headlights allow headlights to follow the steering wheel to focus light on the road ahead, which helps improve drivers' reaction time to potential roadway obstructions (e.g., parked cars). This feature may help reduce visual perceptual errors made by drivers with autism.

Dashboard Navigation Systems provide visual and auditory direction from a driver's origin and destination locations. These systems could reduce the cognitive load on drivers 
with autism. Research indicates that increasing demands on cognitive load could impair executive functioning and driving performance.

Voice Activation Systems allow drivers to keep their eyes on the road and their hands on the wheel by using their voice to control some driving functions (for example, answering the phone, requesting a song, or navigating traffic). The quality and accuracy of the system are critical to avoid frustrations with the system that may distract from the task of driving.

Level 1: Driver Assistance. Driver assistance features in vehicles can take control of the steering wheel or the pedals, but not both, under certain circumstances. Human drivers are still required to monitor the road or take over if the driver assistance features fail to respond appropriately. Such features are widely available in 2018 vehicles; however, they come with an added cost to the purchase of a vehicle. These features include the following.

Lane Keeping Assist adds autonomous intervention to lane-keeping warning systems. The most basic intervention is a bias braking system that brings the front of the vehicle back into the lane. More sophisticated systems use power steering to make small corrections to the vehicle's trajectory. The researched reviewed above indicated that lane-keeping could be a problematic task for some drivers with autism. Automation in this area could minimize driving errors for those individuals.

Adaptive Cruise Control allows a vehicle to autonomously maintain speeds and adjust to the changing traffic flow environment. This system reduces the cognitive and physical demands of driving for those with autism and may improve driving performance. Sometimes certain driving environments required shorter headways, and this system may reduce errors in these situations.

Electronic Stability Control detects loss of steering control due to loss of traction or skidding) and applies the breaks to steer the vehicle back to the road ahead. These systems can reduce accidents for all drivers and not just those with autism.

Assistive Parking Systems help drivers determine whether they have sufficient space to park in either parallel or perpendicular parking spaces and autonomously steer the vehicle into and out of parking spaces. They may also detect and alert drivers to obstacles as a vehicle reverses out of a parking space (e.g., a child who wanders behind a vehicle). Assistive parking systems may help those with spatial and motor integration challenges. They may also allow drivers with autism to feel more confident about driving in busier urban areas that require parallel parking.

Forward-Collision Warnings and Autobrake are features that warn drivers of an impending collision with visual, auditory, and physical cues at a full range of speeds. Some systems can prepare the vehicle for a collision (e.g., precharge the brake). Others can autonomously apply the brake at full or partial forces. The research described above indicates that drivers with autism may be more likely to bump into the vehicle ahead of them. This technology may compensate for some of the cognitive and motor integration challenges of some drivers with autism that contribute to forward collisions. 
Pedestrian Detection and Braking detect pedestrians and bicyclists that may approach and enter a vehicle's path. The systems can automatically apply full or partial forces of the break. This system may assist drivers with autism who experience social-cognitive challenges and/or visual-motor integration challenges.

Level 2: Partial Automation. A vehicle has level 2 automation when it can control both the steering wheel and the pedals at the same time (e.g., adaptive cruise control, lanekeeping, and auto brake). Level 2 automation is often described as "hands off the wheel, eyes on the road." Like level 0 and 1 vehicles, level 2 vehicles still require the driver to actively and continuously monitor their driving of the vehicle, for instance, by responding to traffic signals, changing lanes, and scanning for hazards. Partial automation is less commonly available compared to level 0 and 1 automation, and it comes at a much higher cost. However, multiple autonomous features may further reduce the cognitive load on drivers with autism and improve their driving performance and confidence. Some of the level 2 vehicles that are available to consumers include Audi Traffic Jam Assist, Cadillac Super Cruise, Mercedes-Benz Driver Assistance System, Nissan ProPilot Assist, Tesla Autopilot, and Volvo Pilot Assist.

Level 3: Conditional Automation. At this level, under certain circumstances, the vehicle can take over all driving responsibilities, including monitoring the environment. Human drivers will be prompted by the system to take over control of the vehicle when the system determines that it has encountered a situation that it is not capable of managing. Level 3 automation is often described as "hands off the wheel, eyes off the road, but only sometimes." The Audi Al Traffic Jam Pilot system is available in its A8 sedan, but it is not approved for driving in the U.S. and many other countries. Google achieved conditional automation in 2012 but found that human drivers could not be relied on to re-engage when necessary to avoid hazards rapidly. This may be equally true for individuals with autism. More research is needed to test the safety of these vehicles for use by those with autism.

Level 4: High Automation. These vehicles can drive without a human driver, but only under certain conditions: for example, according to road type, speed, geographic location, and weather. Currently, many level 4 vehicles are undergoing limited pilot testing. Level 4 automation is often described as "hand off the wheel, eyes off the road, mind off but only sometimes." High-automation level 4 vehicles are not currently available to consumers. Shared level 4 vehicles (i.e., vehicles with more than one passenger) may be able to operate without a driver in certain geographic areas in order to expand the reach of affordable on-demand transit service for all people, including those with autism, in areas where is it too costly to provide transit today. Waymo is currently operating pilots with level 4 vehicles without drivers in several areas throughout the U.S. Level 4 automation may be publicly available within the next ten years.

Level 5: Full Automation. The vehicle can operate without any assistance from a human driver under all possible conditions. The human driver must only specify the destination. These vehicles are still under production. However, the barriers of developing and publicly implementing such vehicles make it unlikely that they will be available in the foreseeable future. 


\section{CONCLUSIONS AND POLICY RECOMMENDATIONS}

In this study, the author reviewed the literature, which showed that young adults with autism have significant potential to live independently; however, only $17 \%$ actually do. The inability to drive is a significant barrier to independent living. Many adults with autism face significant challenges in obtaining a driver's license and, even when they do obtain one, they often lack the confidence to use it.

The synthesis of the literature in this study reveals that many of the diagnostic factors associated with autism may contribute to driving difficulties. Broadly, these factors include challenges in executive function, social-cognitive, motor skills, sensory perception, and integration of sensory-motor skills. Drivers must possess adequate executive functioning abilities to monitor and focus on the road ahead and adapt to changes in roadway conditions in order to arrive safely at their destination. Social-cognitive skills include the ability to identify driving hazards that are, by nature, social: for example, predicting the actions of other drivers, pedestrians, and bicyclists, and using non-verbal gestures and signals to communicate. The ability to adequately perceive visual and auditory information is necessary for effective executive functioning. It must be integrated with motor skills (both fine and gross) to execute decisions that safely address changing roadway conditions. The limited number of exploratory research studies that examine the relationship between challenges with these skills and driving performance provides evidence to support linkages.

Currently, available legislation and programs provide funding for adolescents and adults with autism to take individualized transit training courses, use of subsidized or free transit passes, and access to paratransit if safety is a concern. However, most people in the U.S.-not just people with autism—do not have access to transit of high enough quality to enable them to meet their basic travel needs (i.e., work, education, health, shopping, personal, business, and social). SAE level 4 automation is a promising option to expand transit access in lower-density environments affordably. This level of automation allows vehicles to travel at low speeds, on roads that are in excellent condition (i.e., few potholes), and under certain weather conditions (i.e., no snow or rain). In the interim, public funding should be made available to subsidize ride-hailing services when transit is not a feasible travel option. We need funding to implement and research to evaluate the effectiveness of experimental pilots of these programs.

The review of the literature reveals that occupational therapists certified for driving rehabilitation (OT-DRS) can evaluate adolescents and adults with autism for driving competency and specific impairments that might impede driving skill. Children with autism frequently receive occupational therapy to support educational achievement. Schools are required to develop plans to help adolescents with disabilities transition into adulthood. Schools, regional centers, and rehabilitative services should be required to inform adolescents and adults with autism about driving evaluations and special training programs. This therapy should also include experimentation with SAE levels 0 to 2 autonomous vehicle technologies (i.e., warning systems, steering, acceleration/deceleration, and braking systems) that are currently publicly available. If therapists determine a significant benefit, then public funding should be made available to allow people with autism to purchase vehicles with recommended technologies. Currently, public funding is available 
for those with physical disabilities from a variety of public sources to purchase or finance adaptive equipment, such as hand controls, and modify a vehicle to use the equipment and transport wheelchairs. ${ }^{96}$ When determined to be effective, public funding should be available to help those with autism purchase of autonomous vehicle technology, just as funding is available tor those with physical disabilities to modify vehicles with adaptive equipment. A coordinated research evaluation program should be developed and adopted to improve and measure driving outcomes from driver training programs and the use of autonomous vehicle technology. 


\section{ENDNOTES}

1. U.S. Department of Labor's (DOL) Office of Disability Employment Policy (ODEP), "Autonomous Vehicles: Driving Employment for People with Disabilities InformationGathering Session," Washington, D.C., October 26, 2018; Henry Claypool et al., "Self-Driving Cars: The Impact on People with Disabilities," The Ruderman Family Foundation, January 2017; Ashley Halsey III, "Driverless cars promise far greater mobility for the elderly and people with disabilities," The Washington Post, November 23, 2017; Barbara Merrill, Disabled American deserve the Benefits of self-driving cars. The Hill, September 19, 2018.

2. The Senior List, "Driverless Cars for Seniors: Will it improve quality of life?," accessed December 21, 2019, https://www.theseniorlist.com/blog/driverless-cars-for-seniors/.

3. Disability Rights Education and Dense Fund, "Fully Accessible Automous Vehicles Checklist," Working Draft. May 13, 2018.

4. National Council on Disability, "Self-Driving Cars: Mapping Access to a Technological Revolution," November 2, 2015.

5. Srikanth Sarpalli, "Are self-driving cars the future of mobility for disabled people?" The Conversation. October 5, 2017.

6. CDC, 2019

7. Paul T.Shattuck et al. National Autism Indicators Report: High School Students on the Autism Spectrum. Philadelphia, PA: Liver Course Outcomes Program, A.J Drexel Autism Institute.

8. Ibid.

9. CDC, 2019

10. Lynn Newman et al., "The Post-High School Outcomes of Young Adults with Disabilities up to 8 Years after High School: A Report from the National Longitudinal Transition Study-2 (NLTS2). NCSER 2011-3005," National Center for Special Education Research (2011); Paul T. Shattuck et al., "Postsecondary Education and Employment Among Youth with an Austism Spectrum Disorder," Pediatrics 0031-400 (2012); Anne M. Roux et al., "Postsecondary employment experiences among young adults with an autism spectrum disorder," Journal of the American Academy of Child \& Adolescent Psychiatry 52.9 (2013): 931-939.

11. Lynn Newman et al., "The Post-High School Outcomes of Young Adults with Disabilities up to 8 Years after High School: A Report from the National Longitudinal Transition Study-2 (NLTS2). NCSER 2011-3005," National Center for Special Education Research (2011). 
12. Ibid.

13. Paul T. Shattuck et al., "Postsecondary Education and Employment Among Youth with an Austism Spectrum Disorder," Pediatrics 0031-400 (2012).

14. Lynn Newman et al., "The Post-High School Outcomes of Young Adults with Disabilities up to 8 Years after High School: A Report from the National Longitudinal Transition Study-2 (NLTS2). NCSER 2011-3005," National Center for Special Education Research (2011).

15. Anne M. Roux et al., "Postsecondary employment experiences among young adults with an autism spectrum disorder," Journal of the American Academy of Child \& Adolescent Psychiatry 52.9 (2013): 931-939.

16. Paul T. Shattuck et al., "Postsecondary Education and Employment Among Youth with an Austism Spectrum Disorder," Pediatrics 0031-400 (2012); Anne M. Roux et al., "Postsecondary employment experiences among young adults with an autism spectrum disorder," Journal of the American Academy of Child \& Adolescent Psychiatry 52.9 (2013): 931-939.

17. Ibid

18. Paul T. Shattuck et al., "Postsecondary Education and Employment Among Youth with an Austism Spectrum Disorder," Pediatrics 0031-400 (2012).

19. Ibid.

20. Anne M. Roux et al., "Postsecondary employment experiences among young adults with an autism spectrum disorder," Journal of the American Academy of Child \& Adolescent Psychiatry 52.9 (2013): 931-939.

21. Ibid.

22. Derserri Y. Chee et al., "Driving behaviour profile of drivers with autism spectrum disorder (ASD)," Journal of Autism and Developmental Disorders 47.9 (2017): 26582670; Neill B. Cox et al., "Brief report: Driving and young adults with ASD: Parents' experiences," Journal of Autism and Developmental Disorders 42.10 (2012): 22572262; M. Monahan, "Evaluating and treating adolescents with special needs," Driving and community mobility: Occupational therapy strategies across the lifespan (2012): 383-410; J. L. Womack et al., "The big picture: Comprehensive community mobility options," Driving and community mobility: Occupational therapy strategies across the lifespan (2012): 19-46.

23. Anderson, Monica, "Who relies on public transit in the US," Pew Research Center (2016), accessed December 19, 2017.

24. Patty Huang et al., "Factors associated with driving in teens with autism spectrum 
disorders," Journal of Developmental \& Behavioral Pediatrics 33.1 (2012): 70-74; Maria Almberg et al., "Experiences of facilitators or barriers in driving education from learner and novice drivers with ADHD or ASD and their driving instructors," Developmental Neurorehabilitation 20.2 (2017): 59-67; Derserri Y. Chee et al., "Viewpoints on driving of individuals with and without autism spectrum disorder," Developmental Neurorehabilitation 18.1 (2014): 26-36.

25. Neill B. Cox et al., "Brief report: Driving and young adults with ASD: Parents' experiences," Journal of Autism and Developmental Disorders 42.10 (2012): 22572262; Patty Huang et al., "Factors associated with driving in teens with autism spectrum disorders," Journal of Developmental \& Behavioral Pediatrics 33.1 (2012): 70-74; Brian P. Daly et al., "Driving behaviors in adults with autism spectrum disorders," Journal of Autism and Developmental Disorders 44.12 (2014): 3119-3128.

26. Allison E. Curry et al., "Longitudinal study of driver licensing rates among adolescents and young adults with autism spectrum disorder," Autism 22.4 (2018): 479-488.

27. Devajyoti Deka, Cecilia Feeley, and Andrea Lubin, "Travel patterns, needs, and barriers of adults with autism spectrum disorder: Report from a survey," Transportation Research Record: Journal of the Transportation Research Board 4.2542 (2016): 9-16.

28. Lynn Newman et al., "The Post-High School Outcomes of Young Adults with Disabilities up to 8 Years after High School: A Report from the National Longitudinal Transition Study-2 (NLTS2). NCSER 2011-3005," National Center for Special Education Research (2011).

29. Cecilia Feeley, "Evaluating the transportation needs and accessibility issues for adults with autism in New Jersey," 89th Annual Meeting of the Transportation Research Board, Washington, D.C., 2010.

30. Derserri Y. Chee et al., "Viewpoints on driving of individuals with and without autism spectrum disorder," Developmental Neurorehabilitation 18.1 (2014): 26-36; Devajyoti Deka, Cecilia Feeley, and Andrea Lubin, "Travel patterns, needs, and barriers of adults with autism spectrum disorder: Report from a survey," Transportation Research Record: Journal of the Transportation Research Board 4.2542 (2016): 9-16; Elizabeth Sheppard et al., "Difficulties predicting time-to-arrival in individuals with autism spectrum disorders," Research in Autism Spectrum Disorders 28 (2016): 17-23.

31. Devajyoti Deka, Cecilia Feeley, and Andrea Lubin, "Travel patterns, needs, and barriers of adults with autism spectrum disorder: report from a survey," Transportation Research Record: Journal of the Transportation Research Board 4.2542 (2016): 9-16.

32. Ibid.

33. Ibid.

34. Cecilia Feeley, "Evaluating the transportation needs and accessibility issues for adults 
with autism in New Jersey," 89th Annual Meeting of the Transportation Research Board, Washington, D.C., 2010.

35. Deka, Devajyoti, Cecilia Feeley, and Andrea Lubin, "Travel patterns, needs, and barriers of adults with autism spectrum disorder: Report from a survey," Transportation Research Record: Journal of the Transportation Research Board 4.2542 (2016): 9-16.

36. Ibid.

37. Ibid.

38. Ibid.

39. Ami Klin, "Attributing social meaning to ambiguous visual stimuli in higher-functioning autism and Asperger syndrome: The social attribution task," The Journal of Child Psychology and Psychiatry and Allied Disciplines 41.7 (2000): 831-846; Tiziana Zalla et al., "Predicting ensuing actions in children and adolescents with autism spectrum disorders," Experiment; Simon Baron-Cohen, The cognitive neuroscience of autism (2004): 945-948; Rosa M. García-Pérez, R. Peter Hobson, and Anthony Lee, "Narrative role-taking in autism," Journal of Autism and Developmental Disorders 38.1 (2008): 156-168; Ruth Anne Rehfeldt et al., "Assessing relational learning deficits in perspective-taking in children with high-functioning autism spectrum disorder," The Psychological Record 57.1 (2007): 23-47.

40. Elisabeth L. Hill, "Evaluating the theory of executive dysfunction in autism," Developmental Review 24.2 (2004): 189-233; Kimberly A. Fournier et al., "Motor coordination in autism spectrum disorders: A synthesis and meta-analysis," Journal of Autism and Developmental Disorders 40.10 (2010): 1227-1240; David G. Amaral, Cynthia Mills Schumann, and Christine Wu Nordahl, "Neuroanatomy of autism," Trends in Neurosciences 31.3 (2008): 137-145; David R. Simmons et al., "Vision in autism spectrum disorders," Vision Research 49.22 (2009): 2705-2739; Lynne E. Hewitt, "Perspectives on support needs of individuals with autism spectrum disorders: Transition to college," Topics in Language Disorders 31.3 (2011): 273-285; Emma Gowen and Antonia Hamilton, "Motor abilities in autism: A review using a computational context," Journal of Autism and Developmental Disorders 43.2 (2013): 323-344; Derserri Y. Chee et al., "Viewpoints on driving of individuals with and without autism spectrum disorder," Developmental Neurorehabilitation 18.1 (2014): 26-36; Maria Almberg et al., "Experiences of facilitators or barriers in driving education from learner and novice drivers with ADHD or ASD and their driving instructors," Developmental Neurorehabilitation 20.2 (2017): 59-67; Brian P. Daly et al., "Driving behaviors in adults with autism spectrum disorders," Journal of Autism and Developmental Disorders 44.12 (2014): 3119-3128; Sherrilene Classen, Miriam Monahan, and Yanning Wang, "Driving characteristics of teens with attention deficit hyperactivity and autism spectrum disorder," American Journal of Occupational Therapy 67.6 (2013a): 664-673.

41. Akira Miyake et al., "The unity and diversity of executive functions and their contributions to complex 'frontal lobe' tasks: A latent variable analysis," Cognitive Psychology 41.1 
(2000): 49-100; Mark D. Rapport et al., "Do programs designed to train working memory, other executive functions, and attention benefit children with ADHD? A metaanalytic review of cognitive, academic, and behavioral outcomes," Clinical Psychology Review 33.8 (2013): 1237-1252; Elizabeth Walshe et al. "Executive function capacities, negative driving behavior and crashes in young drivers," International Journal of Environmental Research and Public Health 14.11 (2017): 1314.

42. Hannah R. Snyder, "Major depressive disorder is associated with broad impairments on neuropsychological measures of executive function: a meta-analysis and review," Psychological Bulletin 139.1 (2013): 81; Erik G. Willcutt et al., "Validity of the executive function theory of attention-deficit/hyperactivity disorder: a meta-analytic review," Biological Psychiatry 57.11 (2005): 1336-1346; Elizabeth Walshe et al., "Executive function capacities, negative driving behavior and crashes in young drivers," International Journal of Environmental Research and Public Health 14.11 (2017): 1314.

43. Elizabeth Walshe et al., "Executive function capacities, negative driving behavior and crashes in young drivers," International Journal of Environmental Research and Public Health 14.11 (2017): 1314.

44. Philip David Zelazo, Fergus I.M. Craik, and Laura Booth, "Executive function across the life span," Acta Psychologica 115.2-3 (2004): 167-183.

45. Kami Koldewyn et al., "Multiple object tracking in autism spectrum disorders," Journal of Autism and Developmental Disorders 43.6 (2013): 1394-1405.

46. Elizabeth Sheppard et al., "Brief report: Driving hazard perception in autism," Journal of Autism and Developmental Disorders 40.4 (2010): 504-508.

47. Elisabeth L. Hill, "Evaluating the theory of executive dysfunction in autism," Developmental Review 24.2 (2004): 189-233; Derserri Y. Chee et al., "Viewpoints on driving of individuals with and without autism spectrum disorder," Developmental Neurorehabilitation 18.1 (2014): 26-36.

48. Neill B. Cox et al., "Brief report: Driving and young adults with ASD: Parents' experiences," Journal of Autism and Developmental Disorders 42.10 (2012): 22572262; Brian P. Daly, et al. "Driving behaviors in adults with autism spectrum disorders," Journal of Autism and Developmental Disorders 44.12 (2014): 3119-3128.

49. Kimberly A. Fournier et al., "Motor coordination in autism spectrum disorders: a synthesis and meta-analysis," Journal of Autism and Developmental Disorders 40.10 (2010): 1227-1240; Veerle Ross et al., Exploring the driving behavior of youth with an autism spectrum disorder: A driver instructor questionnaire (2015).

50. Veerle Ross et al., Exploring the driving behavior of youth with an autism spectrum disorder: A driver instructor questionnaire (2015); Derserri Y. Chee et al., "Viewpoints on driving of individuals with and without autism spectrum disorder," Developmental Neurorehabilitation 18.1 (2014): 26-36. 
51. Brian P. Daly et al., "Driving behaviors in adults with autism spectrum disorders," Journal of Autism and Developmental Disorders 44.12 (2014): 3119-3128.

52. Derserri Y. Chee et al., "Viewpoints on driving of individuals with and without autism spectrum disorder," Developmental Neurorehabilitation 18.1 (2014): 26-36.

53. Brian P. Daly et al., "Driving behaviors in adults with autism spectrum disorders," Journal of Autism and Developmental Disorders 44.12 (2014): 3119-3128; Derserri Y. Chee et al., "Viewpoints on driving of individuals with and without autism spectrum disorder," Developmental Neurorehabilitation 18.1 (2014): 26-36.

54. Elizabeth Sheppard et al., "Brief report: Driving hazard perception in autism," Journal of Autism and Developmental Disorders 40.4 (2010): 504-508.

55. Simon Baron-Cohen et al., "The autism-spectrum quotient (AQ): Evidence from asperger syndrome/high-functioning autism, males and females, scientists and mathematicians," Journal of Autism and Developmental Disorders 31.1 (2001): 5-17.

56. Sherrilene Classen, Miriam Monahan, and Stephanie Hernandez, "Indicators of simulated driving skills in adolescents with autism spectrum disorder," The Open Journal of Occupational Therapy 1.4 (2013b): 2.

57. Ibid.

58. Ibid.

59. Derserri Y. Chee et al., "Viewpoints on driving of individuals with and without autism spectrum disorder," Developmental Neurorehabilitation 18.1 (2014): 26-36.

60. Ibid.

61. Veerle Ross et al., Exploring the driving behavior of youth with an autism spectrum disorder: A driver instructor questionnaire (2015).

62. Ibid.

63. Stephany M. Cox et al., "Driving simulator performance in novice drivers with autism spectrum disorder: The role of executive functions and basic motor skills," Journal of Autism and Developmental Disorders 46.4 (2016): 1379-1391.

64. Derserri Y. Chee et al., "Driving behaviour profile of drivers with autism spectrum disorder (ASD)," Journal of Autism and Developmental Disorders 47.9 (2017): 2658-2670.

65. Elizabeth Sheppard et al., "Difficulties predicting time-to-arrival in individuals with autism spectrum disorders," Research in Autism Spectrum Disorders 28 (2016): 17-23.

66. Derserri Y. Chee et al., "Driving behaviour profile of drivers with autism spectrum disorder 
(ASD)," Journal of Autism and Developmental Disorders 47.9 (2017): 2658-2670.

67. Ibid.

68. Bryan Reimer et al., "Brief report: Examining driving behavior in young adults with high functioning autism spectrum disorders: A pilot study using a driving simulation paradigm," Journal of Autism and Developmental Disorders 43.9 (2013): 2211-2217.

69. Ibid.

70. Sherrilene Classen, Miriam Monahan, and Stephanie Hernandez, "Indicators of simulated driving skills in adolescents with autism spectrum disorder," The Open Journal of Occupational Therapy 1.4 (2013b): 2.

71. Brian P. Daly et al., "Driving behaviors in adults with autism spectrum disorders," Journal of Autism and Developmental Disorders 44.12 (2014): 3119-3128.

72. Ibid.

73. Stephany M. Cox et al., "Driving simulator performance in novice drivers with autism spectrum disorder: The role of executive functions and basic motor skills," Journal of Autism and Developmental Disorders 46.4 (2016): 1379-1391.

74. Ibid.

75. Ibid.

76. Sherrilene Classen, Miriam Monahan, and Stephanie Hernandez, "Indicators of simulated driving skills in adolescents with autism spectrum disorder," The Open Journal of Occupational Therapy 1.4 (2013b): 2.

77. Veerle Ross et al., Exploring the driving behavior of youth with an autism spectrum disorder: A driver instructor questionnaire (2015).

78. Bryan Reimer et al., "Brief report: Examining driving behavior in young adults with high functioning autism spectrum disorders: A pilot study using a driving simulation paradigm," Journal of Autism and Developmental Disorders 43.9 (2013): 2211-2217.

79. Derserri Y. Chee, et al. "Driving behaviour profile of drivers with autism spectrum disorder (ASD)," Journal of Autism and Developmental Disorders 47.9 (2017): 2658-2670.

80. Sherrilene Classen, Miriam Monahan, and Stephanie Hernandez, "Indicators of simulated driving skills in adolescents with autism spectrum disorder," The Open Journal of Occupational Therapy 1.4 (2013b): 2.

81. Veerle Ross et al., Exploring the driving behavior of youth with an autism spectrum disorder: A driver instructor questionnaire (2015). 
82. Stephany M. Cox et al., "Driving simulator performance in novice drivers with autism spectrum disorder: The role of executive functions and basic motor skills," Journal of Autism and Developmental Disorders 46.4 (2016): 1379-1391.

83. Derserri Y. Chee et al., "Driving behaviour profile of drivers with autism spectrum disorder (ASD)." Journal of Autism and Developmental Disorders 47.9 (2017): 2658-2670.

84. Ibid.

85. Ibid.

86. Veerle Ross et al., Exploring the driving behavior of youth with an autism spectrum disorder: A driver instructor questionnaire (2015).

87. Elizabeth Sheppard et al., "Brief report: Driving hazard perception in autism," Journal of Autism and Developmental Disorders 40.4 (2010): 504-508.

88. Veerle Ross et al., Exploring the driving behavior of youth with an autism spectrum disorder: A driver instructor questionnaire (2015).

89. Sherrilene Classen, Miriam Monahan, and Stephanie Hernandez, "Indicators of simulated driving skills in adolescents with autism spectrum disorder," The Open Journal of Occupational Therapy 1.4 (2013b): 2.

90. Stephany M. Cox et al., "Driving simulator performance in novice drivers with autism spectrum disorder: The role of executive functions and basic motor skills," Journal of Autism and Developmental Disorders 46.4 (2016): 1379-1391.

91. Derserri Y. Chee et al., "Driving behaviour profile of drivers with autism spectrum disorder (ASD)," Journal of Autism and Developmental Disorders 47.9 (2017): 2658-2670.

92. Sherrilene Classen, Miriam Monahan, and Stephanie Hernandez, "Indicators of simulated driving skills in adolescents with autism spectrum disorder," The Open Journal of Occupational Therapy 1.4 (2013b): 2.

93. Veerle Ross et al., Exploring the driving behavior of youth with an autism spectrum disorder: A driver instructor questionnaire (2015).

94. Derserri Y. Chee et al., "Driving behaviour profile of drivers with autism spectrum disorder (ASD)," Journal of Autism and Developmental Disorders 47.9 (2017): 2658-2670.

95. Society of Automotive Engineers (SAE), Taxonomy and Definitions for Terms Related to Driving Automation Systems for On-Roade Motor Vehicles J3016_201806. June 15,2018

96. National Highway Traffic Safety Administration, Adaptiing Motor Vehicles for People with Disabilities, U.S. Department of Transportation, DOT HS 810733 (2015). 


\section{BIBLIOGRAPHY}

Almberg, Maria, et al. "Experiences of facilitators or barriers in driving education from learner and novice drivers with ADHD or ASD and their driving instructors." Developmental Neurorehabilitation 20.2 (2017): 59-67.

Amaral, David G., Cynthia Mills Schumann, and Christine Wu Nordahl. "Neuroanatomy of autism." Trends in Neurosciences 31.3 (2008): 137-145.

Anderson, Monica, "Who relies on public transit in the US?" Pew Research Center, 2016. Retrieved December 19, 2017.

Baron-Cohen, Simon, et al. "The autism-spectrum quotient (AQ): Evidence from asperger syndrome/high-functioning autism, males and females, scientists and mathematicians." Journal of Autism and Developmental Disorders 31.1 (2001): 5-17.

Baron-Cohen, Simon. The Cognitive Neuroscience of Autism (2004): 945-948.

Chee, Derserri Y., et al. "Driving behaviour profile of drivers with autism spectrum disorder (ASD)." Journal of Autism and Developmental Disorders 47.9 (2017): 2658-2670.

Chee, Derserri Y., et al. "Viewpoints on driving of individuals with and without autism spectrum disorder." Developmental Neurorehabilitation 18.1 (2014): 26-36.

Classen, Sherrilene, Miriam Monahan, and Yanning Wang. "Driving characteristics of teens with attention deficit hyperactivity and autism spectrum disorder." American Journal of Occupational Therapy 67.6 (2013a): 664-673.

Classen, Sherrilene, Miriam Monahan, and Stephanie Hernandez. "Indicators of simulated driving skills in adolescents with autism spectrum disorder." The Open Journal of Occupational Therapy 1.4 (2013b): 2.

Henry Claypool et al., "Self-Driving Cars: The Impact on People with Disabilities," The Ruderman Family Foundation, January 2017

Cox, Neill B., et al. "Brief report: Driving and young adults with ASD: Parents' experiences." Journal of Autism and Developmental Disorders 42.10 (2012): 2257-2262.

Cox, Stephany M., et al. "Driving simulator performance in novice drivers with autism spectrum disorder: The role of executive functions and basic motor skills." Journal of Autism and Developmental Disorders 46.4 (2016): 1379-1391.

Curry, Allison E., et al. "Longitudinal study of driver licensing rates among adolescents and young adults with autism spectrum disorder." Autism 22.4 (2018): 479-488. 
Daly, Brian P., et al. "Driving behaviors in adults with autism spectrum disorders." Journal of Autism and Developmental Disorders 44.12 (2014): 3119-3128.

Deka, Devajyoti, Cecilia Feeley, and Andrea Lubin. "Travel patterns, needs, and barriers of adults with autism spectrum disorder: Report from a survey." Transportation Research Record: Journal of the Transportation Research Board 4.2542 (2016): 9-16.

Disability Rights Education and Dense Fund, "Fully Accessible Automous Vehicles Checklist," Working Draft. May 13, 2018.

Feeley, Cecilia, et al. "Detour to the right place: A study with recommendations for addressing the transportation needs and barriers of adults on the autism spectrum in New Jersey" (2015).

Feeley, Cecilia. "Evaluating the transportation needs and accessibility issues for adults on the autism spectrum in New Jersey." 89th Annual Meeting of the Transportation Research Board, Washington, D.C., 2010.

Fournier, Kimberly A., et al. "Motor coordination in autism spectrum disorders: a synthesis and meta-analysis." Journal of Autism and Developmental Disorders 40.10 (2010): 1227-1240.

García-Pérez, Rosa M., R. Peter Hobson, and Anthony Lee. "Narrative role-taking in autism." Journal of Autism and Developmental Disorders 38.1 (2008): 156-168.

Gowen, Emma, and Antonia Hamilton. "Motor abilities in autism: a review using a computational context." Journal of Autism and Developmental Disorders 43.2 (2013): 323-344.

Ashley Halsey III, "Driverless cars promise far greater mobility for the elderly and people with disabilities," The Washington Post, November 23, 2017

Hewitt, Lynne E. "Perspectives on support needs of individuals with autism spectrum disorders: Transition to college." Topics in Language Disorders 31.3 (2011): 273285.

Hill, Elisabeth L. "Evaluating the theory of executive dysfunction in autism." Developmental Review 24.2 (2004): 189-233.

Huang, Patty, et al. "Factors associated with driving in teens with autism spectrum disorders." Journal of Developmental \& Behavioral Pediatrics 33.1 (2012): 70-74.

Klin, Ami. "Attributing social meaning to ambiguous visual stimuli in higher-functioning autism and Asperger syndrome: The social attribution task." The Journal of Child Psychology and Psychiatry and Allied Disciplines 41.7 (2000): 831-846. 
Koldewyn, Kami, et al. "Multiple object tracking in autism spectrum disorders." Journal of Autism and Developmental Disorders 43.6 (2013): 1394-1405.

Barbara Merrill, Disabled American deserve the Benefits of self-driving cars. The Hill, September 19, 2018.

Miyake, Akira, et al. "The unity and diversity of executive functions and their contributions to complex 'frontal lobe' tasks: A latent variable analysis." Cognitive Psychology 41.1 (2000): 49-100.

Monahan, M. "Evaluating and treating adolescents with special needs." Driving and community mobility: Occupational therapy strategies across the lifespan (2012): 383-410.

Monahan, Miriam, Sherrilene Classen, and Patty V. Helsel. "Pre-driving evaluation of a teen with attention deficit hyperactivity disorder and autism spectrum disorder." Canadian Journal of Occupational Therapy 80.1 (2013): 35-41.

National Council on Disability, "Self-Driving Cars: Mapping Access to a Technological Revolution," November 2, 2015.

National Highway Traffic Safety Administration, Adaptiing Motor Vehicles for People with Disabilities, U.S. Department of Transportation, DOT HS 810733 (2015).

Newman, Lynn, et al. "The Post-High School Outcomes of Young Adults with Disabilities up to 8 Years after High School: A Report from the National Longitudinal Transition Study-2 (NLTS2). NCSER 2011-3005." National Center for Special Education Research, 2011.

Rapport, Mark D., et al. "Do programs designed to train working memory, other executive functions, and attention benefit children with ADHD? A meta-analytic review of cognitive, academic, and behavioral outcomes." Clinical Psychology Review 33.8 (2013): 1237-1252.

Rehfeldt, Ruth Anne, et al. "Assessing relational learning deficits in perspective-taking in children with high-functioning autism spectrum disorder." The Psychological Record 57.1 (2007): 23-47.

Reimer, Bryan, et al. "Brief report: Examining driving behavior in young adults with high functioning autism spectrum disorders: A pilot study using a driving simulation paradigm." Journal of Autism and Developmental Disorders 43.9 (2013): 22112217.

Ross, Veerle, et al. Exploring the driving behavior of youth with an autism spectrum disorder: A driver instructor questionnaire (2015).

Roux, Anne M., et al. "Postsecondary employment experiences among young adults 
with an autism spectrum disorder." Journal of the American Academy of Child \& Adolescent Psychiatry 52.9 (2013): 931-939.

Srikanth Sarpalli, "Are self-driving cars the future of mobility for disabled people?" The Conversation. October 5, 2017.

Paul T. Shattuck et al., "Postsecondary Education and Employment Among Youth with an Autism Spectrum Disorder," Pediatrics 0031-400 (2012).

Paul T.Shattuck et al. National Autism Indicators Report: High School Students on the Autism Spectrum. Philadelphia, PA: Liver Course Outcomes Program, A.J Drexel Autism Institute.

Sheppard, Elizabeth, et al. "Brief report: Driving hazard perception in autism." Journal of autism and developmental disorders 40.4 (2010): 504-508.

Sheppard, Elizabeth, et al. "Difficulties predicting time-to-arrival in individuals with autism spectrum disorders." Research in Autism Spectrum Disorders 28 (2016): 17-23.

Simmons, David R., et al. "Vision in autism spectrum disorders." Vision Research 49.22 (2009): 2705-2739.

Society of Automotive Engineers (SAE), Taxonomy and Definitions for Terms Related to Driving Automation Systems for On-Roade Motor Vehicles J3016_201806. June 15,2018

The Senior List, "Driverless Cars for Seniors: Will it improve quality of life?," accessed December 21, 2019, https://www.theseniorlist.com/blog/driverless-cars-forseniors/.

U.S. Center for Disease Control and Prevention (CDC). Autism Spectrum Disorder (ASD). What is Autism Spectrum Disorder? 2018, accessed September 21, 2019. https://www.cdc.gov/ncbddd/autism/facts.html

U.S. Department of Labor's (DOL) Office of Disability Employment Policy (ODEP), "Autonomous Vehicles: Driving Employment for People with Disabilities Information-Gathering Session," Washington, D.C., October 26, 2018

Walshe, Elizabeth, et al. "Executive function capacities, negative driving behavior and crashes in young drivers." International Journal of Environmental Research and Public Health 14.11 (2017): 1314.

Willcutt, Erik G., et al. "Validity of the executive function theory of attention-deficit/ hyperactivity disorder: a meta-analytic review." Biological Psychiatry 57.11 (2005): 1336-1346.

Womack, J. L., et al. "The big picture: Comprehensive community mobility options." 
Driving and community mobility: Occupational therapy strategies across the lifespan (2012): 19-46.

Zalla, Tiziana, et al. "Predicting ensuing actions in children and adolescents with autism spectrum disorders." Experiment.

Zelazo, Philip David, Fergus IM Craik, and Laura Booth. "Executive function across the life span." Acta Psychologica 115.2-3 (2004): 167-183. 


\section{ABOUT THE AUTHOR}

\section{CAROLINE RODIER, PHD}

Dr. Caroline Rodier is a researcher at the Institute of Transportation Studies at the University of California, Davis. Her current research interests include the use of automated vehicle and shared mobility technologies to address the unmet travel needs of disadvantaged populations. This research spans the development and evaluation of pilot programs to scenario simulations with macro-scale activity-based travel models. More importantly, she is the mom of a daughter on the autism spectrum who does not want to drive! 


\section{PEER REVIEW}

San José State University, of the California State University system, and the Mineta Transportation Institute (MTI) Board of Trustees have agreed upon a peer review process required for all research published by MTI. The purpose of the review process is to ensure that the results presented are based upon a professionally acceptable research protocol. 


\author{
Founder, Honorable \\ Norman Mineta (Ex-Officio) \\ Secretary (ret.), \\ US Department of Transportation \\ Chair, \\ Abbas Mohaddes (TE 202I) \\ President \& COO \\ Econolite Group Inc. \\ Vice Chair, \\ Will Kempton (TE 2022) \\ Retired \\ Executive Director, \\ Karen Philbrick, PhD \\ (Ex-Officio) \\ Mineta Transportation Institute \\ San José State University \\ Richard Anderson \\ (Ex-Officio) \\ President \& CEO \\ Amtrak \\ David Castagnetti (TE 202 I) \\ Co-Founder \\ Mehlman Castagnetti \\ Rosen \& Thomas \\ Maria Cino (TE 202 I) \\ Vice President \\ America \& U.S. Government \\ Relations Hewlett-Packard Enterprise
}

\author{
Grace Crunican* \\ (TE 2022) \\ Retired
}

Donna DeMartino (TE 202I)

General Manager \& CEO

San Joaquin Regional Transit District

Nuria Fernandez* (TE 2020)

General Manager \& CEO

Santa Clara Valley

Transportation Authority (VTA)

John Flaherty (TE 2020)

Senior Fellow

Silicon Valley American

Leadership Form

Rose Guilbault (TE 2020)

Board Member

Peninsula Corridor

Joint Powers Board

Ian Jefferies (Ex-Officio)

President \& CEO

Association of American Railroads

Diane Woodend Jones

(TE 2022)

Principal \& Chair of Board

Lea + Elliott, Inc.
Therese McMillan

(TE 2022)

Executive Director

Metropolitan Transportation

Commission (MTC)

Bradley Mims (TE 2020)

President \& CEO

Conference of Minority

Transportation Officials (COMTO)

Jeff Morales (TE 2022)

Managing Principal

InfraStrategies, LLC

Dan Moshavi, PhD

(Ex-Officio)

Dean, Lucas College and

Graduate School of Business

San José State University

Takayoshi Oshima (TE 202 I)

Chairman \& CEO

Allied Telesis, Inc.

Toks Omishakin

(Ex-Officio)

Director

California Department of

Transportation (Caltrans)
Paul Skoutelas (Ex-Officio)

President \& CEO

American Public Transportation

Association (APTA)

Dan Smith (TE 2020)

President

Capstone Financial Group, Inc.

Beverley Swaim-Staley (TE 2022)

President

Union Station Redevelopment

Corporation

\section{Jim Tymon (Ex-Officio)}

Executive Director

American Association of

State Highway and Transportation

Officials (AASHTO)

\section{Larry Willis (Ex-Officio)}

President

Transportation Trades

Dept., AFL-CIO

$(\mathrm{TE})=$ Term Expiration

* = Past Chair, Board of Trustees

\section{Directors}

Karen Philbrick, Ph.D.

Executive Director

Hilary Nixon, Ph.D.

Deputy Executive Director

\section{Asha Weinstein Agrawal,}

\section{Ph.D.}

Education Director

National Transportation Finance

Center Director

\section{Brian Michael Jenkins}

National Transportation Security

Center Director

\title{
Research Associates Policy Oversight Committee
}

Jan Botha, Ph.D.

Civil \& Environmental Engineering

San José State University

Katherine Kao Cushing,

\section{Ph.D.}

Enviromental Science

San José State University

Dave Czerwinski, Ph.D. Marketing and Decision Science San José State University
Frances Edwards,

Ph.D.

Political Science

San José State University

Taeho Park, Ph.D.

Organization and Management

San José State University

\section{Christa Bailey}

Martin Luther King, Jr. Library

San José State University

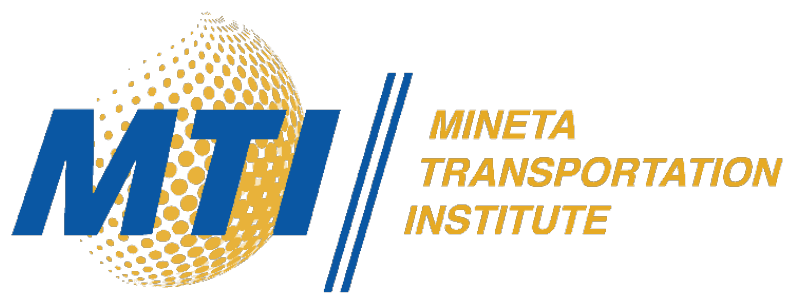

